JOSÉ EDGAR NICOLETTI CARVALHO

\title{
Mecanismos moleculares envolvidos na redução da proliferação de células beta pancreáticas induzida por glicocorticóides
}

Tese apresentada ao Programa de Pósgraduação em Fisiologia e Biofísica do Instituto de Ciências Biomédicas da Universidade de São Paulo para a obtenção do título de Doutor em Ciências.

São Paulo

2010 
JOSÉ EDGAR NICOLETTI CARVALHO

\section{Mecanismos moleculares envolvidos na redução da proliferação de células beta pancreáticas induzida por glicocorticóides}

Tese apresentada ao Programa de Pósgraduação em Fisiologia e Biofísica do Instituto de Ciências Biomédicas da Universidade de São Paulo para a obtenção do título de Doutor em Ciências.

Área de concentração: Fisiologia e Biofísica

Orientadora: Profa. Dra. Silvana Bordin 
DADOS DE CATALOGAÇÃO NA PUBLICAÇÃO (CIP)

Serviço de Biblioteca e Informação Biomédica do

Instituto de Ciências Biomédicas da Universidade de São Paulo

(c) reprodução total

Nicoletti-Carvalho, José Edgar.

Mecanismos moleculares envolvidos na redução da proliferação de células beta pancreáticas induzida por glicocorticóides / José Edgar Nicoletti-Carvalho. -- São Paulo, 2010.

Orientador: Silvana Auxiliadora Bordin da Silva.

Tese (Doutorado) - Universidade de São Paulo. Instituto de Ciências Biomédicas. Departamento de Fisiologia e Biofísica. Área de concentração: Fisiologia Humana. Linha de pesquisa: Biologia Molecular do Pâncreas Endócrino.

Versão do título para o inglês: Underlying molecular mechanisms in the glucocorticoid-induced inhibition of panreatic beta cell proliferation.

Descritores: 1. Ilhotas de Langerhans 2. Gravidez Lactação animal 4. Biologia molecular 5. Diabetes mellitus 6. Glicocorticóides I. Silva, Silvana Auxiliadora Bordin da II. Universidade de São Paulo. Instituto de Ciências Biomédicas. Programa de Pós-Graduação em Fisiologia Humana. III. Título. 


\section{UNIVERSIDADE DE SÃO PAULO \\ INSTITUTO DE CIÊNCIAS BIOMÉDICAS}

Candidato(a): $\quad$ José Edgar Nicoletti-Carvalho.

Título da Tese: $\quad$ Mecanismos moleculares envolvidos na redução da proliferação de células beta pancreáticas induzida por glicocorticóides .

Orientador(a): $\quad$ Silvana Auxiliadora Bordin da Silva.

A Comissão Julgadora dos trabalhos de Defesa da Tese de Doutorado, em sessão pública realizada a considerou
( ) Aprovado(a)
( ) Reprovado(a)

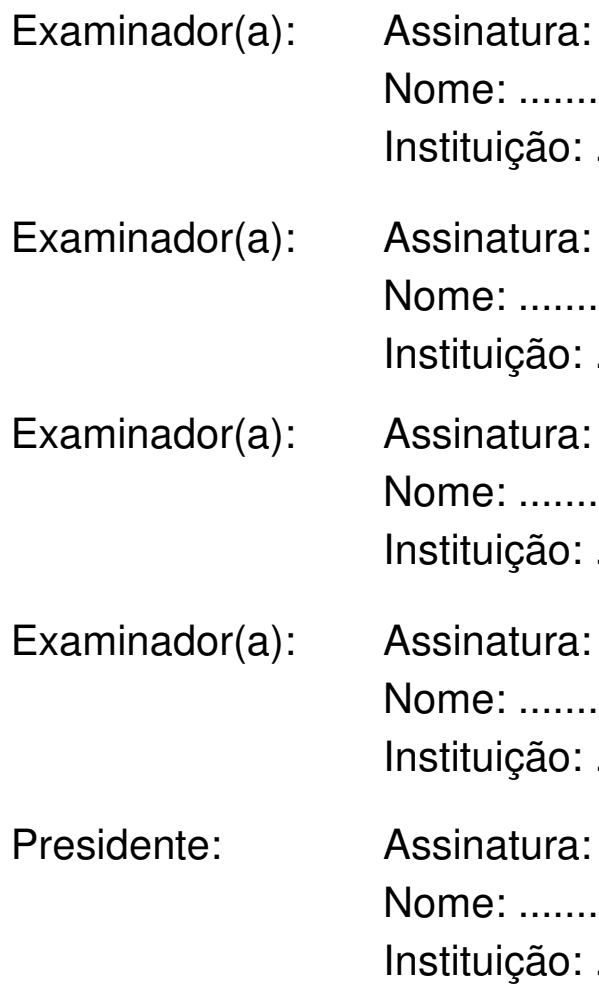




\section{CERTIFICADO DE ISENÇÃO}

Certificamos que o Protocolo CEP-ICB No 278, referente ao projeto intitulado: "Participação da via das Map Kinases na manutenção e viabilidade da célula Beta Pancreática " sob a responsabilidade de José Edgar Nicoletti Carvalho, foi analisado na presente data pela CEEA COMISSÃO DE ÉtTCA EM EXPERIMENTAÇÃo ANimAL e pela CEPSH COMISSÃO DE ÉTICA EM PESQUisA COM SERES HUMANOS, tendo sido deliberado que o referido projeto não envolve manipulação animal ou humana que justifique uma aprovação quanto aos princípios éticos exigidos por ambas as Comissões.

São Paulo, 09 de dezembro de 2008.

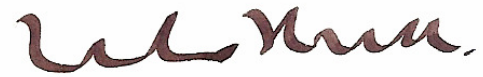

Prof. Dr. Wothan TaVARES DE LiMa Coordenador da CEEA - ICB/USP

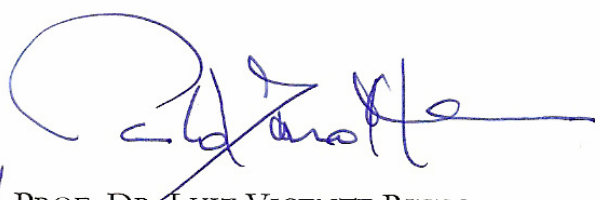

Prof. Dr. Luiz Vicente RizZO

Coordenador da CEPsh - ICB/USP 


\section{AGRADECIMENTOS}

À minha orientadora, Silvana Bordin, por toda dedicação ao meu trabalho e pelos ensinamentos ministrados ao longo de minha iniciação científica, mestrado e doutorado. Em momentos de dificuldade fui sempre amparado pelo seu brilhantismo.

A meu grande amigo, Gabriel Anhê, meu maior incentivador e mentor intelectual.

À Gisele Couto, pelo companheirismo e apoio incondicional.

Aos meus amigos que pertencem ou pertenceram ao Laboratório de Biologia Molecular com os quais tive a oportunidade de contar com a ajuda, aprender e compartilhar amizade.

A todos os amigos dos laboratórios do Departamento de Fisiologia e Biofísica com quem convivi ao longo desses anos.

Aos professores do Departamento de Fisiologia e Biofísica que auxiliaram na execução deste trabalho. De maneira especial agradeço aos Professores Maria Tereza Nunes, Ubiratan Fabres Machado e Maria Lucia Giannella.

À Secretaria de Pós-Graduação do Departamento de Fisiologia e Biofísica, especialmente ao José Maria.

À Biblioteca do Instituto de Ciências Biomédicas da Universidade de São Paulo.

Ao Conselho Nacional de Desenvolvimento Científico e Tecnológico (CNPq).

À Fundação de Amparo à Pesquisa do Estado de São Paulo (FAPESP). 


\section{RESUMO}

NICOLETTI-CARVALHO, J. E. Mecanismos moleculares envolvidos na redução da proliferação de células beta pancreáticas induzida por glicocorticóides. 2010. 59f. Tese (Doutorado em Fisiologia Humana) - Instituto de Ciências Biomédicas, Universidade de São Paulo, São Paulo, 2010.

Durante a gravidez, o pâncreas endócrino materno sofre alterações morfológicas e funcionais que resultam no aumento da massa de células beta e da secreção de insulina. Nos estágios finais da gestação ocorre aumento dos níveis plasmáticos de glicocorticóides, os quais parecem estar envolvidos na diminuição da secreção e da proliferação das células beta. Este fenômeno, que ocorre no período compreendido entre o final da gravidez e o inicio da lactação, promove a reversão fisiológica da adaptação funcional que se fez necessária durante a gravidez. Assim, estudamos mecanismos moleculares envolvidos na redução de proliferação destas células, utilizando as linhagens RINm5F e MIN6 como modelos experimentais. Sabese que as proteínas cinases reguladas por sinais extracelulares (ERK) estão envolvidas no crescimento e sobrevida celular. Os resultados demonstram que o glicocorticóide sintético dexametasona diminui a fosforilação das ERK-1/2 e aumenta a expressão da MKP-1, uma fosfatase de MAPK. O bloqueio da expressão de MKP-1 impediu o efeito inibitório da dexametasona sobre a fosforilação das ERK-1/2 e sobre a proliferação de células beta. Assim, a dexametasona aumenta a expressão de MKP-1 na célula beta, que por sua vez desfosforila as ERK-1/2, bloqueando a ação proliferativa induzida por estas proteínas. Este mecanismo deve estar envolvido no remodelamento pancreático pós-natal induzido pelos glicocorticóides.

Palavras-chave: Diabetes melitus. Ilhotas de Langerhans. Gravidez. 


\begin{abstract}
NICOLETTI-CARVALHO, J. E. Underlying molecular mechanisms in the glucocorticoidinduced inhibition of pancreatic beta cell proliferation. 2010. 59p. Ph. D. Thesis (Human Physiology) - Instituto de Ciências Biomédicas, Universidade de São Paulo, São Paulo, 2010.

During pregnancy, maternal pancreatic islets undergo morphofunctional changes that increase beta cell mass and insulin secretion. At late stages of pregnancy there is an increase in plasma glucocorticoid levels that inhibit beta cell proliferation and beta cell function. This situation, which occurs in a period between late pregnancy and early stages of lactation, counteracts the functional gain established throughout pregnancy. In this work, using the beta cell lineages RINm5F and MIN6, we studied the molecular mechanisms involved in the impaired beta cell proliferation. It is well known that extracellular regulated kinases (ERKs) are involved in cellular growth and survival. Our results show that dexamethasone, a synthetic glucocorticoid, reduced ERK-1/2 phosphorylation and increased the expression of the dual specificity phosphatase MKP-1. MKP-1 knockdown impaired the inhibitory effect of dexamethasone on ERK-1/2 phosphorylation and beta cell proliferation. In conclusion, dexamethasone induces MKP-1 expression, which dephosphorylates ERK-1/2, thus repressing its mitogenic action. This mechanism could take part in the glucocorticoid-induced reestablishment of endocrine pancreatic mass post-pregnancy.
\end{abstract}

Key words: Diabetes Mellitus. Islets of Langerhans. Pregnancy. 


\section{SUMÁRIO}

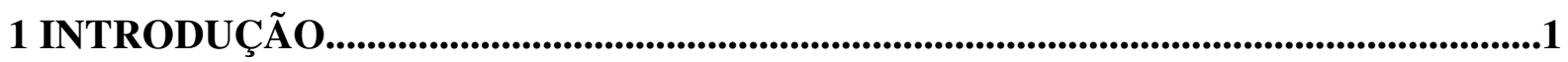

1.1 Via de sinalização das MAPK..............................................................................................................4

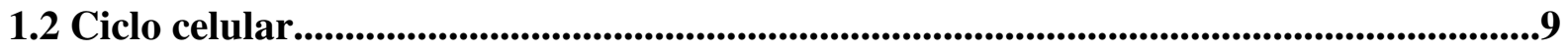

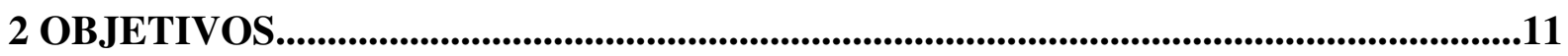

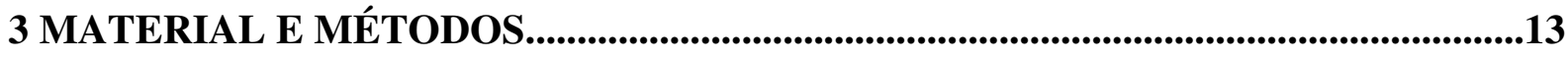

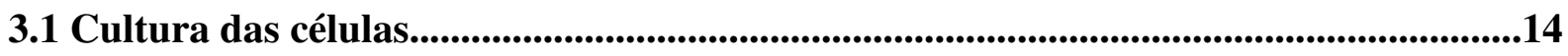

3.2 Incubações das células com drogas específicas..........................................................14

3.3 Extração de proteínas......................................................................................................................................15

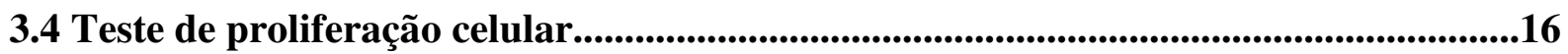

3.5 Teste de transfecção das células para o bloqueio da expressão de MKP-1..................17

3.6 Teste de proliferação de células submetidas ao bloqueio da expressão de MKP-1.....18

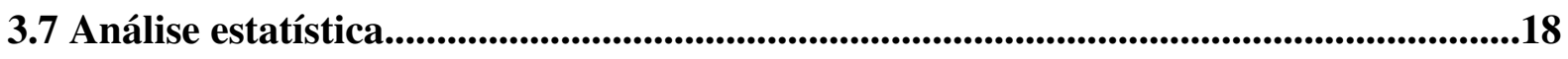

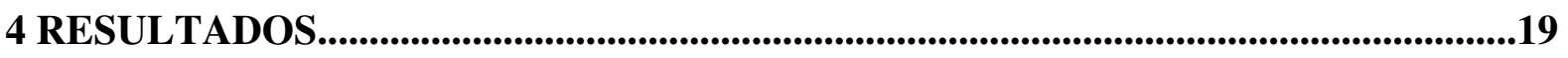

4.1 Modulação da fosforilação das proteínas ERK-1/2 após tratamento de células

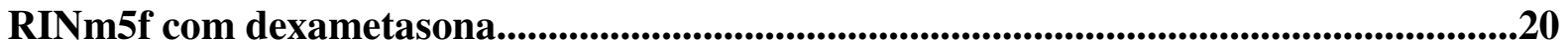

4.2 Modulação da fosforilação das ERK-1/2 em células RINm5f com o bloqueio da expressão protéica e bloqueio da atividade de fosfatases................................................25

4.3 Verificação da modulação da fosforilação das proteínas ERK-1/2 após tratamento de

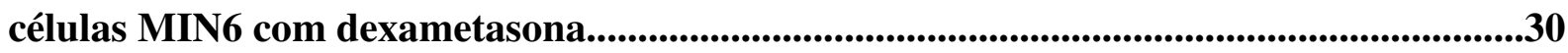

4.4 Modulação da fosforilação das ERK-1/2 em células MIN6 com o bloqueio da

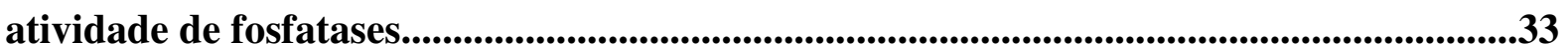

4.5 Proliferação celular por incorporação de bromo deoxiuridina em células MIN6 tratadas com DEX............................................................................................................................................34

4.6 Bloqueio da expressão de MKP-1 nas células MIN6................................................34

4.7 Proliferação das células MIN6 tratadas com DEX com prévia inibição da expressão

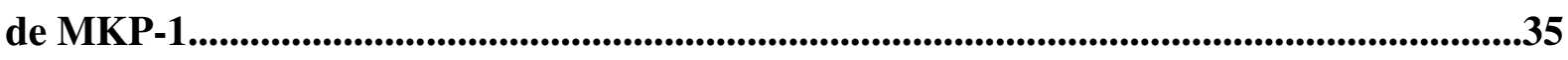

4.8 Modulação da expressão de proteínas do ciclo celular em células MIN6 tratadas com

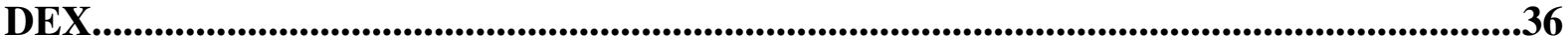

5 DISCUSSÃO

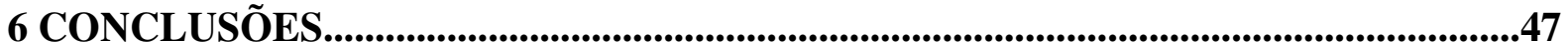

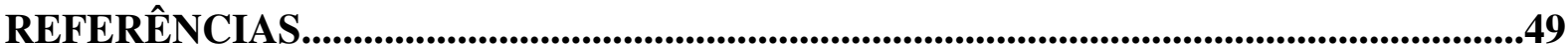


INTRODUÇÃO 


\section{INTRODUÇÃO}

O conhecimento dos mecanismos de sobrevivência das células beta pancreáticas é fundamental para a prevenção e tratamento de doenças relacionadas à secreção de insulina como o diabetes mellitus do tipo 1 e 2. Desta forma, a busca de informações sobre a regulação da função destas células ainda é uma questão central para o entendimento dos mecanismos desencadeadores destes problemas. Consoante a isto, é de fundamental importância o estudo dos eventos bioquímicos resultantes da resposta celular a fatores externos que regem a viabilidade e a manutenção da função destas células.

A manutenção da massa tecidual é resultante de mecanismos dos quais as células se utilizam tais como: controle da taxa de renovação celular a partir de células precursoras ou de células diferenciadas pré-existentes; controle da taxa de morte celular; e controle do volume celular. Embora seja um tecido dinâmico, as taxas de replicação e apoptose da ilhota pancreática ao longo da vida adulta são consideradas baixas. Uma das mais notáveis condições onde esta taxa de renovação celular é drástica e coordenadamente alterada é a transição entre a gestação e a lactação (SCAGLIA; SMITH; BONNER-WEIR, 1995; FINEGOOD et al., 1997; SCAGLIA et al., 1997). Assim, este constitui um excelente período para o estudo da fisiologia de manutenção da massa de células da ilhota pancreática.

No início do desenvolvimento da gravidez, o pâncreas endócrino materno passa por alterações morfológicas e funcionais que resultam na expansão do volume das ilhotas (HELLMAN, 1960; MARYNISSEN; AERTS; VAN ASSCHE, 1983), consequência do aumento da taxa de proliferação de células beta (TEITELMAN; ALPERT; HANAHAN, 1988). Concomitantemente à proliferação, ocorre o aumento da síntese e secreção de insulina (PARSONS; BRELJE; SORENSON, 1992). Estas alterações são necessárias para garantir a homeostase glicêmica durante um período caracterizado pelo desenvolvimento de resistência 
à insulina pela mãe, uma vez que a captação de glicose diminui durante a gravidez, tanto em humanos como em roedores (HORNNES, 1985; ROSSI et al., 1993). Desse modo, ocorre um direcionamento do fluxo de glicose para o feto, essencial para o desenvolvimento deste.

Em roedores, o aumento da proliferação das células beta ocorre ao redor do décimo dia de gestação, com pico ao redor do décimo quarto dia (SORENSON; BRELJE, 1997; KAWAI; KISHI, 1999) correspondente na mulher ao final do $2^{\circ}$ trimestre. As evidências acumuladas nas últimas décadas mostram que o lactogênio placentário (PL) e a prolactina (PRL) induzem as alterações morfofuncionais da ilhota pancreática observadas na gravidez, como por exemplo, o aumento da atividade mitogênica; a redução da apoptose; e o aumento da sensibilidade à glicose (BENDER; CHICKERING, 1985; BRELJE; SORENSON, 1991; SORENSON; BRELJE, 1997; NIELSEN et al., 2001).

Nos estágios finais da gestação ocorre diminuição da massa de células beta (MARYNISSEN; AERTS; VAN ASSCHE, 1983). Este fenômeno está associado ao início da involução da ilhota no período pós-parto e, portanto, à reversão fisiológica da adaptação funcional que se fez necessária durante a gravidez.

Paralelamente à diminuição da massa de células beta que ocorre nesse período, verificou-se que a partir do décimo quinto dia de gestação até o parto, os níveis de corticosterona se elevam no plasma das ratas (DUPOUY; COFFIGNY; MAGRE, 1975; COHEN, 1976; MARTIN, et al., 1977) resultando nos característicos altos níveis de glicocorticóides circulantes nos estágios finais da gestação.

Weinhaus et al. (2000) mostraram que células beta induzidas à proliferação com PRL tinham este efeito inibido quando eram co-tratadas com o glicocorticóide dexametasona (DEX). Adicionalmente, verificou-se que o tratamento isolado com o glicocorticóide levou ao aumento da apoptose desas células. Assim, os glicocorticóides, em concentrações equivalentes àquelas encontradas no plasma materno durante os estágios finais da gravidez, 
contra-regulam os efeitos de ganho de função da célula beta induzidos por PRL (WEINHAUSS et al., 2000; SHAO; QIAO; FRIEDMAN, 2004). Desse modo, a recuperação da atividade e da massa de células beta no período pós-parto tem como provável causa o aumento da concentração dos glicocorticóides circulantes.

Para exercer seus efeitos intracelulares, o glicocorticóide atravessa a membrana plasmática em direção ao citoplasma onde se liga ao receptor de glicocorticóide que, por sua vez, se desliga do complexo protéico formado pelas heat shock proteins (HSPs). Uma vez livre das HSPs, o glicocorticóide, dimerizado com o seu receptor, transloca-se para o núcleo e se liga a elementos responsivos de glicocorticóides em genes específicos do DNA. Assim, pela regulação da transcrição de genes-alvo, os glicocorticóides exercem suas ações fisiológicas (WRIGHT, et al., 1992; SCHONEVELD; GAEMERS; LAMERS, 2004).

As diferentes respostas celulares desencadeadas pelos glicocorticóides variam de acordo com o tipo celular envolvido e com as quantidades de receptores que constituem a célula do tecido em questão. São diversas as respostas fisiológicas das células em decorrência da ligação destes hormônios, por exemplo: indução ou inibição tanto da proliferação quanto da apoptose (LANGEVELD et al., 1992; ZIBERA et al., 1992; KUDAWARA et al., 2001; YAMAMOTO et al., 2002; HERR et al., 2007). Neste trabalho estudamos o efeito antiproliferativo dos glicocorticóides através de dois mecanismos de resposta intracelular: (1) modulação da via de sinalização relacionada à proliferação celular e (2) modulação da expressão de proteínas ligadas ao ciclo celular.

\subsection{Via de sinalização das MAPK}

As proteínas cinases ativadas por mitógenos MAPK (mitogen activated protein kinases) constituem uma grande rede de proteínas intracelulares que regulam uma variedade de processos fisiológicos tais como crescimento celular, diferenciação, mobilidade e morte 
celular. Dentre as MAPK, a família de serina/treonina cinases conhecida por cinases reguladas por sinais extracelulares (ERKs) têm função principalmente relacionada ao crescimento e sobrevivência celular (LEWIS; SHAPIRO; AHN, 1998; PEARSON et al., 2001; JOHNSON; LAPADAT, 2002; YOON; SEGER, 2006).

Proteínas cinases são enzimas que ligam covalentemente o grupamento fosfato das moléculas de ATP às cadeias laterais dos resíduos de aminoácidos (serina, treonina e tirosina) de proteínas celulares. A fosforilação pode levar a proteína a alterar sua atividade enzimática, induzir sua ligação ou separação de outras moléculas, alterar sua localização na célula, tornála mais propensa a degradação por proteases, entre outras diversas conseqüências. De modo geral, em ativações de alguns tipos de vias de sinalização intracelular, estímulos específicos induzem iniciação da cascata de sinalização cujo sinal se propaga, através de fosforilações catalisadas por proteínas cinases, levando à associação de proteínas por interação de domínios SH-2 (src-homology-binding-domain-2) de uma proteína com domínios YXXQ (onde Y representa o aminoácido tirosina, $\mathrm{X}$ representa qualquer aminoácido e $\mathrm{Q}$ representa o aminoácido glutamina) de outra proteína que apresenta a tirosina fosforilada. De acordo com o observado por estímulo com fator de crescimento epidermal (EGF) e fator de crescimento derivado de plaquetas (PDGF), a proteína SHP-2 (tirosina fosfatase 2 que contém domínio SH-2) é fosforilada em tirosina e interage com a proteína de ligação do receptor do fator de crescimento (Grb2). A Grb2 ligada a SHP-2 interage com a son of sevenless (SOS) e finalmente, o recrutamento da SOS ao complexo do receptor na membrana permite a ativação da Ras, que resulta na ativação da cascata Ras-Raf, e induz a fosforilação da MEK que, por sua vez, ativa as ERKs via fosforilação em treonina e tirosina destas moléculas (ROBINSON et al., 2002; HEINRICH et al., 2003) (figura 1). 


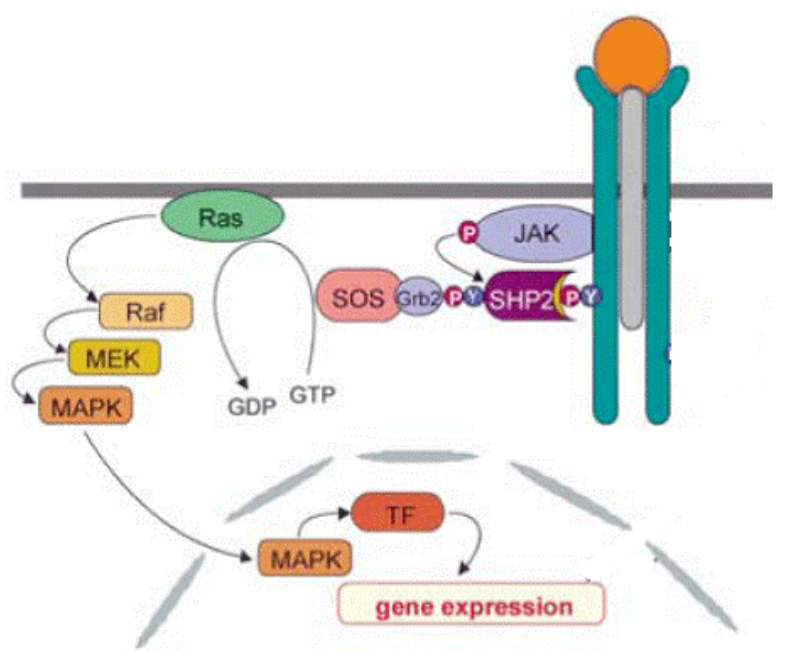

Figura 1. Representação esquemática da ativação das MAPKs por estímulos extracelulares FONTE: adaptado de Heinrich et al., 2003.

As duas isoformas mais conhecidas das ERKs, as MAPKs p44 e p42 (ERK-1/2), são expressas na célula beta pancreática, onde modulam a proliferação celular (LINGOHR et al., 2002). Diversos hormônios, citocinas, fatores de crescimento, estímulos osmóticos e de estresse celular estão envolvidos na ativação da via de sinalização que pertencem as ERKs. PRL, um dos mais potentes fatores de crescimento para as ilhotas pancreáticas, e interleucina6 (IL-6), uma citocina inflamatória que exerce efeito de manutenção da sobrevida da célula beta, estão entre os ativadores das ERK-1/2 (NIELSEN et al., 1999; HEINRICH et al., 2003; AMARAL et al., 2003; PARK et al., 2003; BORDIN et al., 2004; CHOI, et al., 2004). Entretanto, os mecanismos envolvidos na regulação da atividade das ERKs e os efeitos biológicos fundamentais na célula beta pancreática ainda não foram totalmente esclarecidos.

Uma vez fosforiladas e ativadas, as ERK-1/2 podem fosforilar e estimular a atividade de diversos fatores de transcrição, regulando deste modo a expressão gênica. $O$ fator de transcrição c-Myc é ativado pela ERK-2 quando fosforilado em serina, e sua ativação está envolvida na proliferação celular (SEARS et al., 2000). As ERK-1/2 também fosforilam, em dois resíduos distintos de treonina, a proteína Spl, a qual tem papel fundamental na expressão 
de genes envolvidos na progressão do ciclo celular e crescimento tumoral (MILANINIMONGIAT; POUYSSÉGUR; PAGÉS, 2002). As ERK-1/2 podem também interferir no metabolismo celular regulando a atividade de proteínas citoplasmáticas. Um exemplo disto foi verificado em uma linhagem de células beta tumorais MIN6, onde as ERK-1/2 fosforilam uma proteína envolvida na maquinaria de exocitose dos grânulos de insulina interferindo na secreção do hormônio (LONGUET et al., 2005).

A magnitude e duração da ativação das ERK são fundamentais para a determinação da resposta fisiológica (SABBAGH et al., 2001; EBISUYA; KONDOH; NISHIDA, 2005). Isto realça a importância de mecanismos regulatórios que determinam a atividade destas proteínas e, portanto, a modificação no grau de fosforilação dessas proteínas por fosfatases constitui um ponto essencial no controle de sua função.

Para sua ativação, as ERK-1/2 necessitam ser fosforiladas em ambos resíduos de treonina e tirosina, e para serem desativadas necessitam somente da desfosforilação de um desses resíduos (DICKINSON; KEYSE, 2006). Assim, fosfatases específicas para tirosina, fosfatases de serina/treonina e fosfatases de especificidade dupla (tirosina/treonina) podem desativar as ERK-1/2. Dentre as fosfatases específicas para resíduos de tirosina podem ser citadas a STEP (Protein-tyrosine phosphatase striatum-enriched) e a HePTP (Hematopoietic protein-tyrosine phosphatase); dentre as fosfatases de resíduos de serina/treonina encontramse as PP2A (protein phosphatase 2A) e PP2C (protein phosphatase 2C); e dentre as fosfatases de especificidade dupla (tirosina/treonina) DUSP (dual-specificity phosphatase), as mais conhecidas são as MKPs (Mitogen Activated Protein Kinase Phosphatases) (KEYSE, 2000; SAXENA; MUSTELIN, 2000; KONDOH; NISHIDA, 2007).

Até o momento, dentro do grupo das DUSP se conhecem 11 proteínas do subgrupo MKPs, sendo divididas em três famílias de acordo com similaridade estrutural da proteína e do gene, especificidade ao substrato e localização na célula. A família de MKPs do tipo 1 é 
constituída por fosfatases constitutivamente nucleares e são estimuladas pelos mesmos agentes que ativam as MAPKs. Desta forma, são consideradas como um importante mecanismo para regulação negativa da ativação desta via mitogênica. Nesta família encontram-se as MKP-1, MKP-2, DUSP2 e DUSP5. A família de MKPs do tipo 2 é constituída de fosfatases de localização citoplasmática e é composta pela MKP-3, MKP-4 e MKP-X. A família do tipo 3 é composta pelas fosfatases MKP-5, MKP-7 e DUSP8, que desfosforilam somente as MAPKs JNK e p38, sem nenhum tipo de ação sobre as ERK-1/2 (KEYSE, 2000; THEODOSIOU; ASHWORTH, 2002; CAMPS; NICHOLS; ARKINSTALL, 2006).

MKP-1 foi a primeira fosfatase de MAPK descrita, e sua expressão gênica é controlada rapidamente após a exposição de células a fatores de crescimento (CHARLES; ABLER; LAU, 1992). O estudo desta fosfatase desperta interesse especial, uma vez que sua cinética de expressão induzida em fibroblastos é temporalmente coincidente com a desativação da ERK-2 (SUN et al., 1993).

Foi demonstrado que a resposta anti-inflamatória dos glicocorticóides está relacionada ao aumento a expressão de MKP-1 (KASSEL et al., 2001; CHEN et al., 2002; LASA et al., 2002). Em osteoblastos, este mecanismo regulatório promove a diminuição da atividade das ERK-1/2 e, consequentemente, a redução da proliferação celular (ENGELBRECHT et al., 2003). A participação das MKPs na função e proliferação das células beta dependente de ERK-1/2 ainda não foi demonstrada.

Estudos realizados em nosso laboratório mostraram que o glicocorticóide sintético dexametasona aumenta a expressão do mRNA de MKP-1 em células beta tumorais de rato RINm5F (ANHE, 2007). Este aumento também foi observado em ilhotas de ratas isoladas no início da lactação, período que coincide com a redução da proliferação e aumento da apoptose (SCAGLIA; SMITH; BONNER-WEIR, 1995). Desta maneira, nossa hipótese é a de que o 
rápido remodelamento do pâncreas endócrino desencadeado pelo pico de glicocorticóides do final da gestação seja, pelo menos em parte, dependente da diminuição da fosforilação e da atividade das ERK-1/2, em resposta ao aumento da expressão de MKP-1.

É importante destacar que, no período pós-parto, ocorre redução da massa da ilhota mesmo na presença de altos níveis de PRL circulante. In vitro, as ações da PRL não são completamente revertidas pela retirada do hormônio, mas sim pela adição de dexametasona no meio de cultura (WEINHAUS et al., 2000). Estas observações sugerem que a reversão da adaptação funcional ocorrida durante gravidez envolve um controle sofisticado de regulação de expressão gênica mediada pela ação destes dois hormônios.

\subsection{Ciclo celular}

A progressão do ciclo celular é controlada pela ativação sequiencial e temporária de uma família proteínas denominadas cinases dependentes de ciclinas (CDKs) que permitem uma ordenada sucessão das fases do ciclo celular G1, S, G2 e M. CDKs são ativadas somente quando formam um complexo protéico com a ciclina correspondente. Os seguintes complexos: ciclinaD/CDK4-6, ciclinaE/CDK2, ciclinaA/CDK2, e ciclinaB/CDK1 promovem, respectivamente, progressão na fase G1; transição para a replicação de DNA na fase $S$; progressão na fase $S$ e transição para a fase $G 2$; e, finalmente, a transição da fase G2

para M, permitindo o início do processo de mitose (PINES, 1999; NURSE, 2002; MALUMBRES; BARBACID, 2005; HOCHEGGER; TAKEDA; HUNT, 2008). A regulação da atividade das CDKs é exercida por um variedade de mecanismos que incluem associação com ciclinas e inibidores protéicos, fosforilação/desfosforilação, e síntese/degradação de ciclinas (FÉLIX et al., 1990; MORGAN, 1995).

A atividade dos complexos ciclina/CDK é regulada por fosforilação/desfosforilação e associação reversível com os inibidores protéicos p21 ou p27 (MORGAN, 1995; HITOMI et 
al., 2006). A proteína de retinoblastoma (pRb) e o fator de transcrição E2F têm como função, respectivamente, inibir e promover a passagem pelas fases do ciclo celular. Assim, os complexos ciclina/CDK controlam a atividade de $\mathrm{pRb}$ e E2F por fosforilação destas moléculas. A proteína $\mathrm{pRb}$, quando desfosforilada, portanto ativada, leva à repressão transcricional de genes envolvidos na progressão do ciclo celular, assim, quando desativada leva à indução de estímulos mitogênicos em diferentes tecidos por promover a progressão do ciclo celular (GÉRARD; GOLDBETER, 2009).

Os glicocorticóides têm sido descritos preferencialmente como indutores de efeito anti-proliferativo em diversos tipos celulares (HERR et al., 2007; MATTERN; BÜCHLER; HERR, 2007). Estudos em linhagens celulares indicam que o efeito anti-proliferativo deve ocorrer por um bloqueio reversível da progressão da fase G1 do ciclo celular (GOYA et al., 1993; BRAUNSCHWEIGER; STRAGAND; SCHIFFER, 1978). Foi demonstrado que o tratamento com glicocorticóides induz este efeito de inibição do ciclo celular pelo aumento da expressão da proteína inibidora p21 em células de neuroblastoma (SENGUPTA et al., 2000) e de hepatoma (CHA, et al., 2007). 
OBJETIVOS 


\section{OBJETIVOS}

A fim de se estudar o efeito dos glicocorticóides na proliferação de células beta pancreáticas e o envolvimento da via das MAPKs nesse processo, o objetivo deste trabalho foi investigar em linhagens tumorais de células beta pancreáticas de camundongo (MIN6) e de rato $(\mathrm{RINm} 5 \mathrm{f})$ :

1- Se a dexametasona é responsável pela diminuição de proliferação de células beta;

2- A participação de fosfatases no controle da proliferação destas células;

3- A expressão de proteínas envolvidas nos processos de proliferação celular. 
MATERIAL E MÉTODOS 


\section{MATERIAL E MÉTODOS}

\subsection{Cultura das células}

Células de insulinoma de rato RINm5f e células de insulinoma de camundongo MIN6 foram mantidas em meio de cultura RPMI-1640 com glicose $(11,1 \mathrm{mM})$, soro fetal bovino $10 \%$ (Cultlab, Brasil), penicilina $(100 \mathrm{U} / \mathrm{ml})$ e estreptomicina $(0,1 \mathrm{mg} / \mathrm{ml})$ (Invitrogen, EUA) em atmosfera de $5 \% \mathrm{CO}_{2}$, a $37{ }^{\circ} \mathrm{C}$ com umidade relativa do ar de $90 \%$. A concentração de glicose na qual as células foram cultivadas $(11,1 \mathrm{mM})$ está de acordo com os valores usualmente utilizados para essas linhagens tumorais de células beta (HUISING et al., 2009; LORTZ et al., 2000). As células foram cultivadas até atingirem confluência de aproximadamente $90 \%$ da área da garrafa. Após isto, as células eram submetidas aos tratamentos detalhados adiante.

\subsection{Incubações das células com drogas específicas}

No tratamento com o glicocorticóide sintético dexametasona (Sigma, EUA), eram acrescidas ao meio de cultura as soluções alcoólicas concentradas de dexametasona para atingirem as concentrações desejadas $(10-1000 \mathrm{mM})$. O solvente da dexametasona, etanol, também era adicionado nas amostras controle. Para a inibição da tradução geral das moléculas de mRNA, e conseqüente inibição da síntese protéica, foi realizado o tratamento das células com ciclohexamida $(40 \mu \mathrm{g} / \mathrm{mL})$ (Calbiochem, EUA) por 1 hora antes da adição de dexametasona. A Inibição da atividade das fosfatases de tirosina foi feita através do uso de ortovanadato de sódio $(1,0-1,5 \mu \mathrm{M})$ (Sigma, EUA) previamente ao tratamento das células com a dexametasona. O íon ortovanadato se liga reversivelmente aos sítios catalíticos da maioria das proteínas tirosina fosfatase. Esse composto é usualmente utilizado no preparo de soluções tampão com o objetivo de inibir a atividade catalítica dessas enzimas. 


\subsection{Extração de proteínas}

Antes da extração de proteínas, as células foram lavadas duas vezes com solução salina tamponada com fosfato $\left(\mathrm{NaCl} 1,37 \mathrm{M}, \mathrm{KCl} 27 \mathrm{mM}, \mathrm{Na}_{2} \mathrm{HPO}_{4} 101,4 \mathrm{mM}, \mathrm{K}_{2} \mathrm{HPO}_{4}\right)$ adicionada de inibidores de fosfatases de tirosina (1 $\mathrm{mM}$ de ortovanadato de sódio) e de serina/treonina ( $5 \mathrm{mM}$ de fluoreto de sódio) a $4{ }^{\circ} \mathrm{C}$ para depois serem removidas da superfície interna da garrafa com o uso de rodo de plástico apropriado. Após remoção e coleta, as células foram sedimentadas por centrifugação a $1.000 \mathrm{~g}$ por 10 minutos a $4{ }^{\circ} \mathrm{C}$. As células sedimentadas foram lisadas e homogeneizadas com o uso de um sonicador em tampão de extração (1\% de dodecil sulfato de sódio, 100 mM de Tris [pH 7,4], $100 \mathrm{mM}$ de pirofosfato de sódio, $100 \mathrm{mM}$ de fluoreto de sódio, $10 \mathrm{mM}$ de EDTA e $10 \mathrm{mM}$ de ortovanadato de sódio), incubadas por 10 minutos a $96^{\circ} \mathrm{C}$ e em seguida centrifugadas para a remoção do material insolúvel (10.000 g por 10 minutos a $\left.4{ }^{\circ} \mathrm{C}\right)$. Parte do sobrenadante foi utilizada para determinação do conteúdo protéico por espectrofotometria com reagente Bradford (Biorad, CA, USA); o restante foi diluído em tampão Laemmli (LAEMMLI, 1997) (1:5 v/v) contendo ditiotreitol $100 \mathrm{mM}$, incubados por 10 minutos a $96{ }^{\circ} \mathrm{C}$. Quantidades iguais de proteína das diferentes amostras foram submetidas à separação eletroforética em gel de poliacrilamida $10 \%(\% \mathrm{~T})$ com dodecil sulfato de sódio (SDS-PAGE) em aparelho para minigel (Mini Protean III, Bio-Rad, CA, USA). Após a separação eletroforética no gel, as proteínas foram transferidas para uma membrana de nitrocelulose (Biorad, CA, USA). As membranas foram incubadas em solução bloqueadora contendo $5 \%(\mathrm{~g} / \mathrm{mL})$ de leite em pó desnatado em solução basal (10 $\mathrm{mM}$ de Tris, $150 \mathrm{mM}$ de $\mathrm{NaCl}$ e $0,02 \%$ de Tween) por 2 horas a temperatura ambiente. Após o bloqueio, as membranas foram incubadas por 4 horas a temperatura ambiente em solução basal com 3\% de albumina de soro bovino (BSA) com os seguintes anticorpos: anti ERK-1/2 (Upstate, EUA), anti p-ERK-1/2 tyr, anti MKP-1, anti MKP-2, anti CD1, anti CDK4, anti p21 e anti $\beta$-actina (Santa Cruz Biotechnology, EUA). Após marcação 
com anticorpo primário, as membranas foram incubadas por 1 hora com anticorpo secundário apropriado conjugado à peroxidase (Amershan Pharmacia, UK) em solução basal com 1\% de leite em pó desnatado. Após lavagens da membrana, foram adicionados os reagentes de detecção do kit de quimioluminescência (ECL, Amershan Pharmacia, UK). As membranas foram, então, expostas durante tempos variados a filmes de raios-X. Depois de revelados, esses filmes foram submetidos à análise de densitometria óptica pelo software Scion Image (Scioncorp, NIH, USA).

\subsection{Teste de proliferação celular}

Para verificação da proliferação das células MIN6, foi utilizado o Kit BrdU Cell Proliferation Assay (cat. $\mathrm{n}^{\mathrm{o}}$ 2750, Chemicon International, EUA). O bromo deoxiuridina (BrdU) é um nucleosídeo sintético análogo à timidina. BrdU é incorporado às recém sintetizadas fitas de DNA de células em processo de replicação, substituindo a timidina. Assim, quanto maior a incorporação de BrdU, maior é a atividade proliferativa das células analisadas, uma vez que isto indica o aumento da síntese de DNA.

O experimento foi realizado de acordo com as instruções do fabricante do Kit. Assim, as células MIN6 foram repicadas 4 × $10^{4}$ células por poço (em placas de cultura de 96 poços) e mantidas em cultura por $24 \mathrm{~h}$ em meio RPMI-1640 com glicose $(11,1 \mathrm{mM})$, soro fetal bovino $10 \%$, penicilina $(100 \mathrm{U} / \mathrm{ml})$ e estreptomicina $(0,1 \mathrm{mg} / \mathrm{ml})$. Subsequentemente, as células foram tratadas com dexametasona $(100 \mathrm{nM})$ por $72 \mathrm{~h}$ em meio de cultura RPMI-1640 com glicose $(11,1 \mathrm{nM})$, antibióticos e com soro fetal bovino a $0,1 \%$. BrdU foi adicionado nas últimas $5 \mathrm{~h}$ de tratamento com DEX. Após este período as células foram fixadas na superfície da placa onde foi realizada a desnaturação do DNA. Os poços foram lavados com tampão de lavagem para a posterior incubação por $1 \mathrm{~h}$ com o anticorpo anti-BrdU. Os poços foram novamente lavados com tampão de lavagem para a incubação por 30 min com o anticorpo 
secundário conjugado à peroxidase. Após este período foi realizada uma lavagem final com água destilada para a posterior incubação por $30 \mathrm{~min}$ em local protegido de luz com o substrato da peroxidase. A reação foi interrompida com a adição de uma solução de ácido sulfúrico. Finalmente foram realizadas as leituras espectrofotométricas das amostras da placa com um feixe de luz de comprimento de onda de $450 \mathrm{~nm}$. A absorbância da amostra é diretamente proporcional à quantidade de BrdU incorporado.

\subsection{Teste de transfecção das células para o bloqueio da expressão de MKP-1}

O bloqueio da expressão de MKP-1 foi realizado de acordo com as instruções do fabricante do MKP-1 siRNA (sc-35938, Santa Cruz Biotechnology, EUA). Inicialmente foi realizado o experimento para o teste da eficiência da transfecção. Assim, as células MIN6 foram repicadas $4 \times 10^{5}$ células por poço (em placas de cultura de 6 poços) e mantidas em cultura por $24 \mathrm{~h}$ em meio RPMI-1640 com glicose $(11,1 \mathrm{mM})$, soro fetal bovino $10 \%$ e antibióticos. As células aderidas foram lavadas duas vezes com meio livre de soro e antibióticos (Opti-MEM, Invitrogen, Carlsbad, CA) para depois serem incubadas em $1 \mathrm{~mL}$ deste meio contendo MKP-1 siRNA (concentração final de aproximadamente $80 \mathrm{nM}$ ) previamente misturado a $8 \mu \mathrm{L}$ de siRNA Transfection Reagent (sc-29529 Santa Cruz Biotechnology, EUA). Após 7 horas em cultura, foi adicionado ao poço $1 \mathrm{~mL}$ de meio RMPI contendo $20 \%$ de soro fetal bovino, $22.2 \mathrm{mM}$ de glicose, penicilina (200 U/mL) e estreptomicina $(0,2 \mathrm{mg} / \mathrm{ml})$ com a finalidade de se compor as concentrações usuais destes componentes para a permanência em cultura das células. Após $18 \mathrm{~h}$, foi realizada a troca do meio de cultura por meio RPMI com concentrações usuais de glicose, soro fetal bovino e antibiótico. As células foram mantidas por mais $48 \mathrm{~h}$ em cultura. Após este período, foi realizado o tratamento das células com DEX $(100 \mathrm{nM})$ por 6 horas para a realização de extração protéica e western blotting. 


\subsection{Teste de proliferação de células submetidas ao bloqueio da expressão de MKP-1}

Para se verificar a proliferação das células MIN6 submetidas ao bloqueio da expressão de MKP-1, foram semeadas $4 \times 10^{4}$ células por poço (em placas de cultura de 96 poços) e mantidas em cultura por $24 \mathrm{~h}$ em meio RPMI-1640 com glicose $(11,1 \mathrm{mM})$, soro fetal bovino 10\% e antibióticos. Após este período, foi realizada a transfecção como citado anteriormente, porém, de maneira diferente, os poços foram incubados com 50 uL da solução de transfecção (MKP-1 siRNA previamente misturado ao siRNA Transfection Reagent). Após 7 horas em cultura, foram adicionados ao poço $50 \mathrm{uL}$ de meio RMPI contendo $20 \%$ de soro fetal bovino, $22.2 \mathrm{mM}$ de glicose, penicilina $(200 \mathrm{U} / \mathrm{mL})$ e estreptomicina $(0,2 \mathrm{mg} / \mathrm{ml}) \mathrm{com}$ a finalidade de se compor as concentrações usuais destes componentes para a permanência em cultura das células. Após 18 h, as células foram tratadas com dexametasona (100 nM) em meio de cultura RPMI-1640 com glicose $(11,1 \mathrm{nM})$, antibióticos e com soro fetal bovino a $0,1 \%$ para permanecerem em cultura por $72 \mathrm{~h}$. BrdU foi adicionado nas últimas $5 \mathrm{~h}$ de tratamento com DEX. Após este procedimento as células foram submetidas ao teste de proliferação descrito anteriormente.

\subsection{Análise estatística}

Os resultados foram expressos como média \pm erro padrão da média (EPM) e analisados estatisticamente por teste t de Student ou análise de variância (ANOVA de uma via) com pós-teste de Tukey, quando apropriado. 
RESULTADOS 


\section{RESULTADOS}

\subsection{Modulação da fosforilação das proteínas ERK-1/2 após tratamento de células RINm5f com dexametasona}

Inicialmente foram realizados experimentos para verificação do tempo de tratamento com dexametasona (DEX) em que ocorre diminuição da fosforilação das ERK-1/2. Para isto, as células RINm5F foram tratadas com DEX (100 nM) durante os seguintes períodos: 15 min; 30 min; 2 h; 4 h; 6 h; 8 h. Após isto, procedeu-se com a extração de proteínas totais para a realização do blotting. As membranas de nitrocelulose foram incubadas com os seguintes anticorpos: anti p-ERK-1/2 (tyr), anti ERK-1/2, anti MKP-1, anti MKP-2 e anti $\beta$-actina.

A fosforilação das ERK-1/2 apresentou aumento nos tratamentos de 15 e 30 min com DEX e redução nos tratamentos de 4, 6 e 8 h (figura 2).
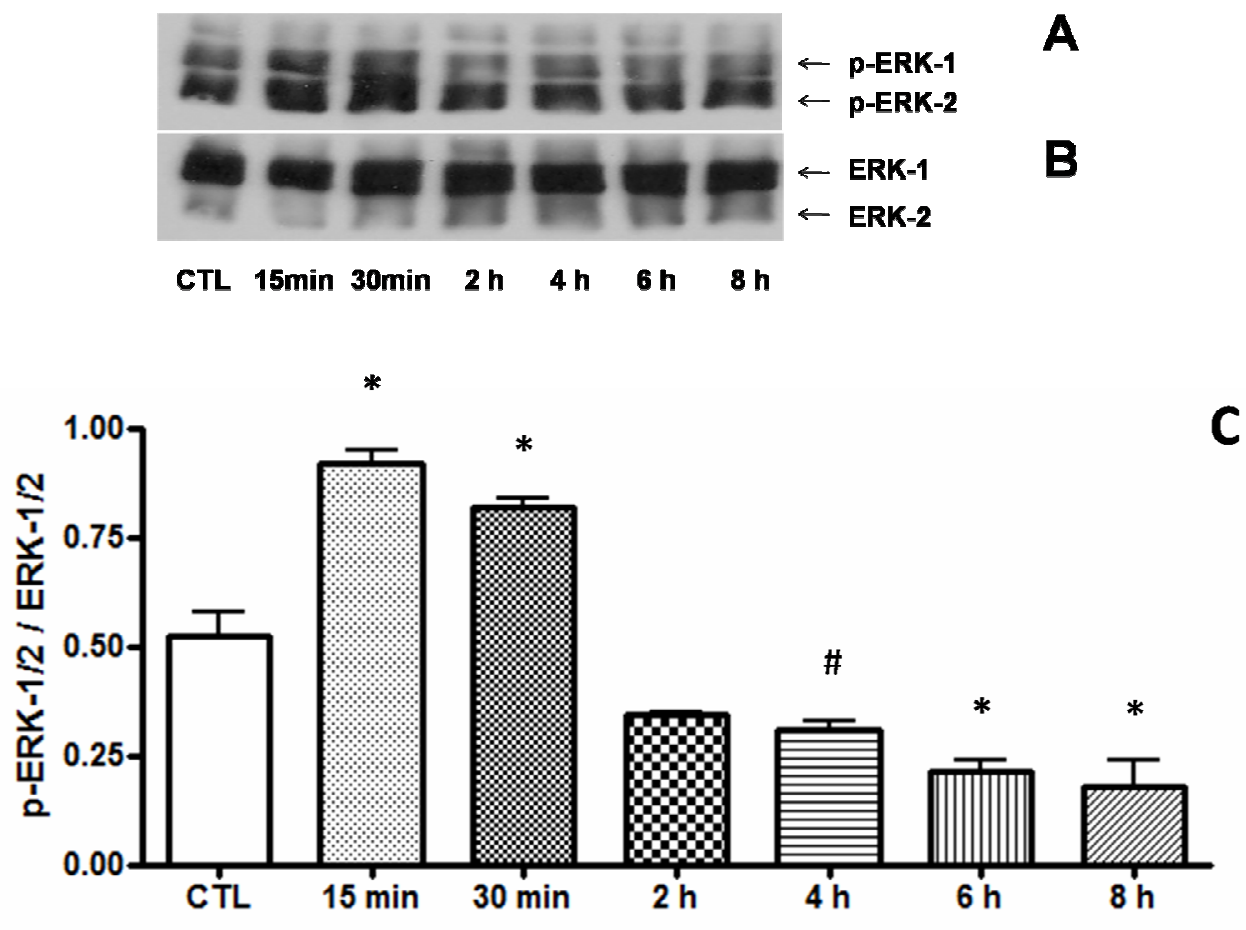

Figura 2. Fosforilação em tirosina de ERK-1/2. Células RINm5f tratadas com DEX (100 nM). (A) immunoblotting com anticorpo anti p-ERK-1/2 (Tyr). (B) immunoblotting com anticorpo anti ERK1/2. (C) Gráfico da razão dos valores das densitometrias ópticas obtidas em A e B (p-ERK-1/2 / ERK-1/2). Os tempos de tratamento com DEX estão indicados no gráfico. ${ }^{*} p<0,01 ; \# p<0,05$ vs. CTL. $(\mathrm{N}=3)$. 
Para estes mesmos períodos de tratamento com DEX, foi verificada a expressão das fosfatases MKP-1 (figura 3) e MKP-2 (figura 4).

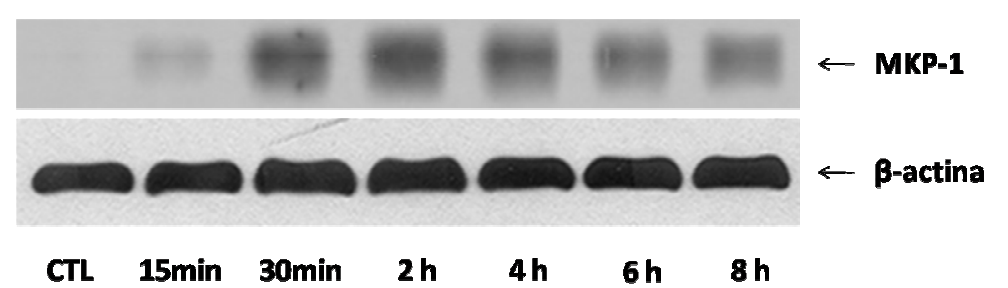

A

B

CTL 15min 30min $2 \mathrm{~h} \quad 4 \mathrm{~h} \quad 6 \mathrm{~h} \quad 8 \mathrm{~h}$

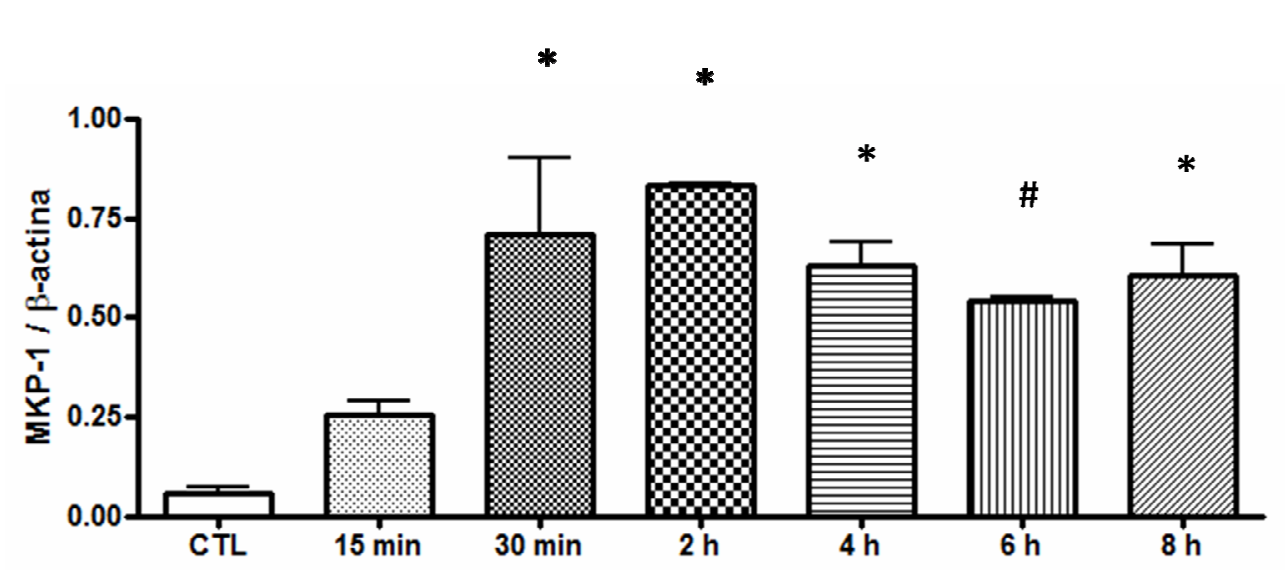

Figura 3. Expressão da fosfatase MKP-1. Células RINm5f tratadas com DEX (100 nM). (A) immunoblotting com anticorpo anti MKP-1. (B) immunoblotting com anticorpo anti $\beta$-actina. (C) Gráfico da razão dos valores das densitometrias ópticas obtidas em A e B (MKP-1 / $\beta$-actina). Os tempos de tratamento com DEX estão indicados no gráfico. ${ }^{*} p<0,01 ; \# p<0,05$ vs. CTL. $(\mathrm{N}=3)$.

DEX induziu rapidamente (30 min) a expressão de MKP-1. De maneira inversa, DEX induziu a diminuição da expressão da fosfatase MKP-2. 

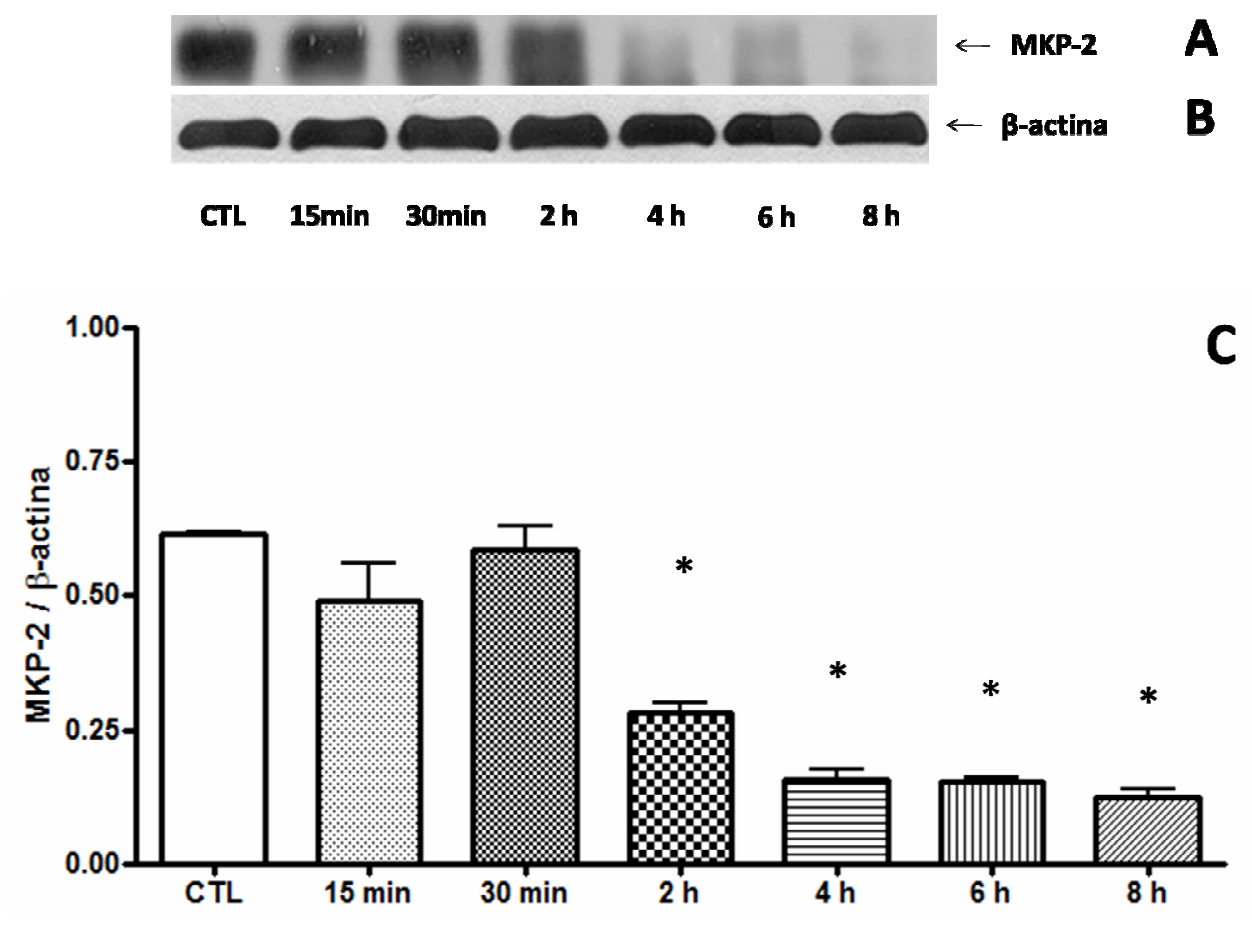

Figura 4. Expressão da fosfatase MKP-2. Células RINm5f tratadas com DEX (100 nM). (A) immunoblotting com anticorpo anti MKP-2. (B) immunoblotting com anticorpo anti $\beta$-actina. (C) Gráfico da razão dos valores das densitometrias ópticas obtidas em A e B (MKP-2 / $\beta$-actina). Os tempos de tratamento com DEX estão indicados no gráfico. ${ }^{*} p<0,01 v s$. CTL. $(\mathrm{N}=4)$.

$\mathrm{Na}$ sequência, foi realizado o experimento de dose-resposta no qual as células foram incubadas em diferentes concentrações de DEX por 6 h de tratamento. Assim, após a extração de proteínas totais e realização do blotting, as membranas foram incubadas com os seguintes anticorpos: anti p-ERK-1/2 (tyr), anti ERK-1/2, anti MKP-1, anti MKP-2 e anti $\beta$-actina. As fosforilações das ERK-1/2 apresentam-se diminuídas nas concentrações de $50 \mathrm{nM}$ e superiores (Figura 5). 


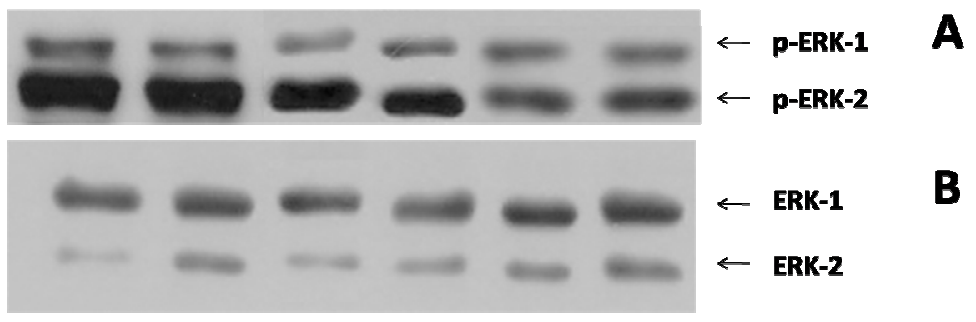

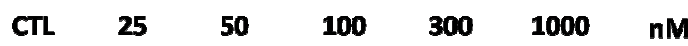

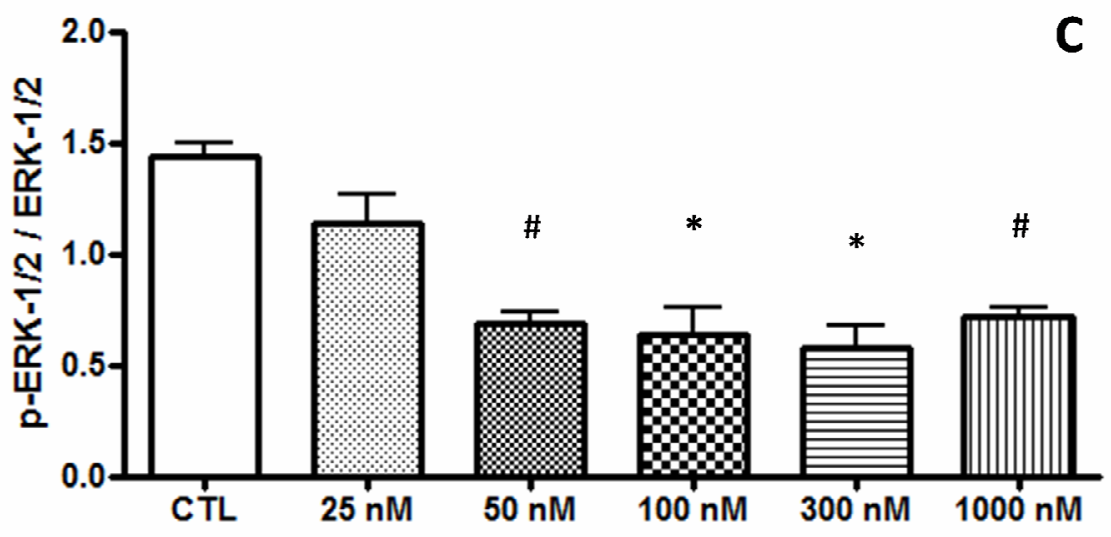

Figura 5. Fosforilação em tirosina de ERK-1/2. Células RINm5f tratadas com DEX por 6 h. (A) immunoblotting com anticorpo anti p-ERK-1/2 (Tyr). (B) immunoblotting com anticorpo anti ERK1/2. (C) Gráfico da razão dos valores das densitometrias ópticas obtidas em A e B (p-ERK-1/2 / ERK-1/2). As concentrações utilizadas de DEX estão indicadas no gráfico. ${ }^{*} p<0,01 ; \# p<0,05$ vs. CTL. $(\mathrm{N}=3$ a 6$)$.

A expressão das fosfatases MKP-1 e MKP-2 foi alterada nos tratamentos com diferentes concentrações de DEX (figuras 6 e 7). O glicocorticóide sintético DEX induziu diminuição na fosforilação das ERK-1/2 e aumento da expressão de MKP-1. 


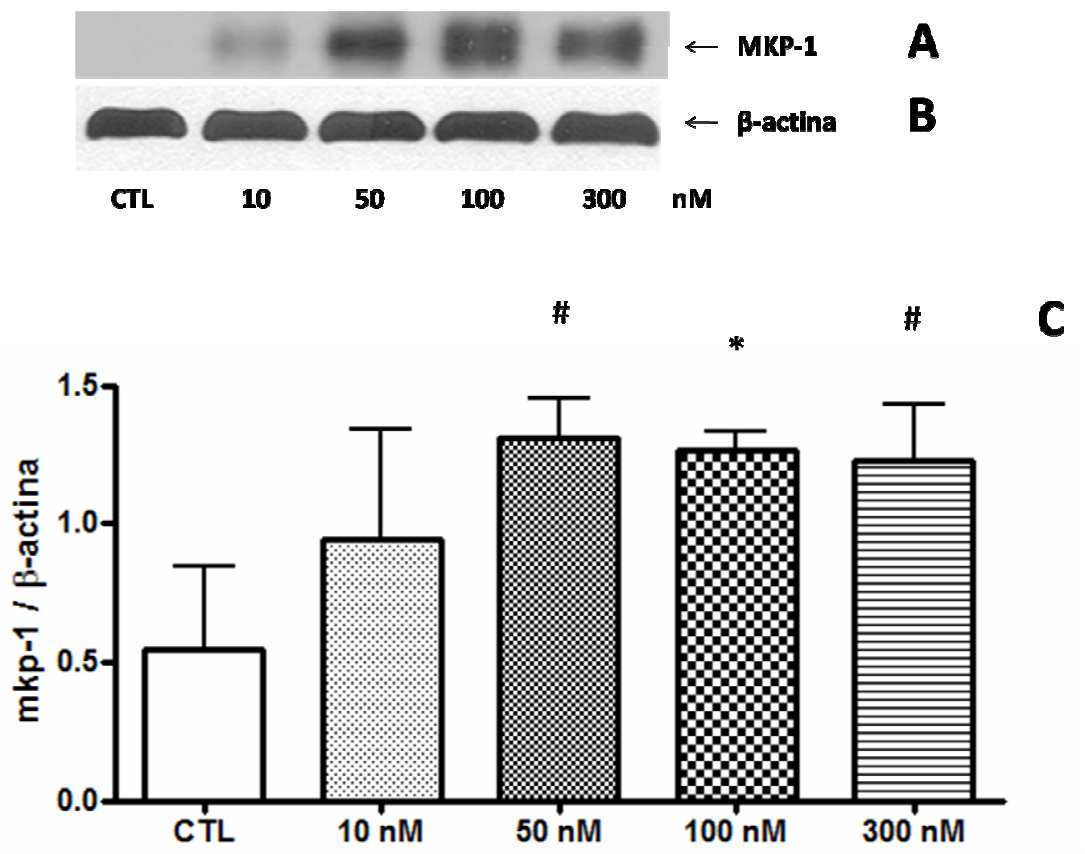

Figura 6. Expressão da fosfatase MKP-1. Células RINm5f tratadas com DEX por 6 h. (A) immunoblotting com anticorpo anti MKP-1. (B) immunoblotting com anticorpo anti $\beta$-actina. (C) Gráfico da razão dos valores das densitometrias ópticas obtidas em A e B (MKP-1 / $\beta$-actina). As concentrações utilizadas de DEX estão indicadas no gráfico. ${ }^{*} p<0,01$; \# $p<0,05$ vs. CTL. $(\mathrm{N}=3)$.
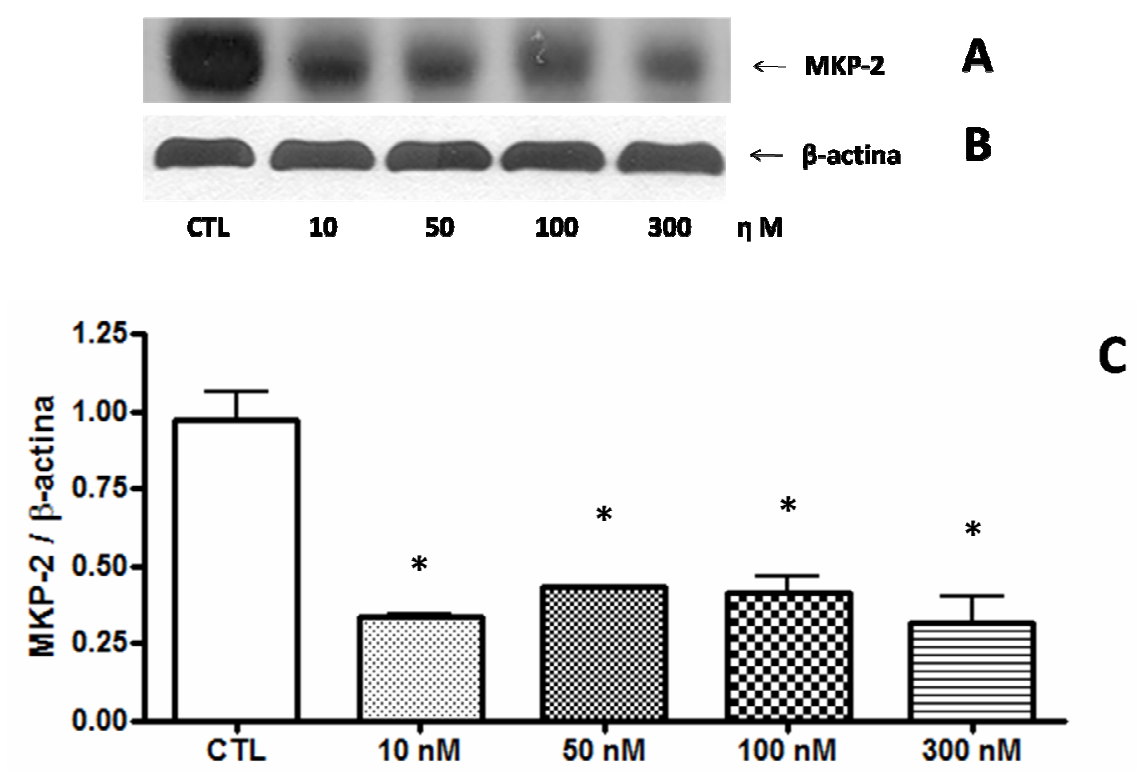

Figura 7. Expressão da fosfatase MKP-2. Células RINm5f tratadas com DEX por 6 h. (A) immunoblotting com anticorpo anti MKP-2. (B) immunoblotting com anticorpo anti $\beta$-actina. (C) Gráfico da razão dos valores das densitometrias ópticas obtidas em A e B (MKP-2 / $\beta$-actina). As concentrações utilizadas de DEX estão indicadas no gráfico. ${ }^{*} p<0,01 v s$. CTL. $(\mathrm{N}=5)$. 


\subsection{Modulação da fosforilação das ERK-1/2 em células RINm5f com o bloqueio da expressão protéica e bloqueio da atividade de fosfatases}

No intuito de se investigar o mecanismo envolvido na diminuição da fosforilação das ERK-1/2 induzido pelo tratamento por $6 \mathrm{~h}$ com $100 \mathrm{nM}$ de DEX, foi utilizado um inibidor de síntese protéica, ciclohexamida $(\mathrm{CHX})$, com o objetivo de impedir a expressão imediata da fosfatase MKP-1. Assim, as células foram pré-tratadas com ciclohexamida (40 $\mu \mathrm{g} / \mathrm{mL})$ por 1 $\mathrm{h}$ antes da adição de DEX. Terminado o tempo de incubação com as drogas, foi realizada a extração de proteínas para posterior detecção das proteínas ERK-1/2, ERK-1/2 fosforiladas e MKP-1.

O tratamento prévio com CHX impediu o aumento da expressão de MKP-1 induzido por DEX (figura 8).
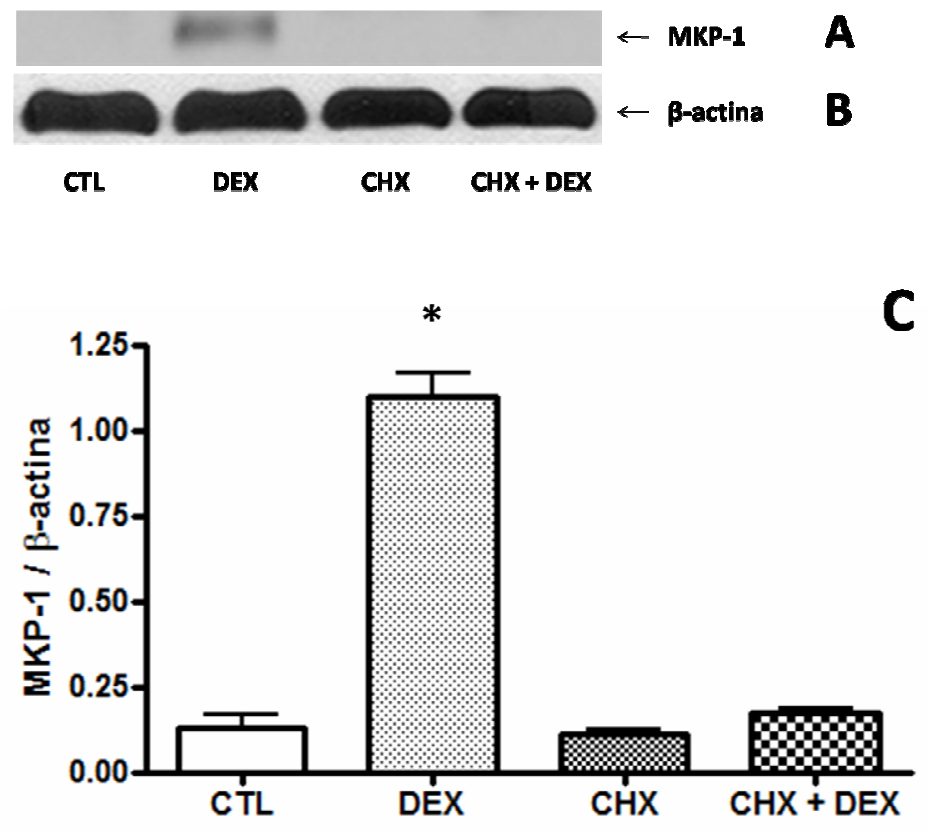

Figura 8. Expressão da fosfatase MKP-1. Células RINm5f pré-tratadas por $1 \mathrm{~h}$ com CHX $(40 \mu \mathrm{g} / \mathrm{mL})$ e posteriormente com DEX (100 nM) por $6 \mathrm{~h}$. (A) immunoblotting com anticorpo anti MKP-1. (B) immunoblotting com anticorpo anti $\beta$-actina. (C) Gráfico da razão dos valores das densitometrias ópticas obtidas em A e B (MKP-1 / $\beta$-actina). * $p<0,01$ vs. CTL. $(\mathrm{N}=4)$.

Como não houve aumento da expressão de MKP-1 quando as células pré-tratadas com CHX eram posteriormente tratadas com DEX, partiu-se para a verificação da fosforilação das 
ERK-1/2 com o intuito de se verificar a ocorrência de diminuição desta fosforilação com a inibição da expressão de MKP-1. A diminuição da fosforilação das ERK-1/2 induzida por DEX não ocorreu quando o pré-tratamento com CHX era realizado (figura 9).

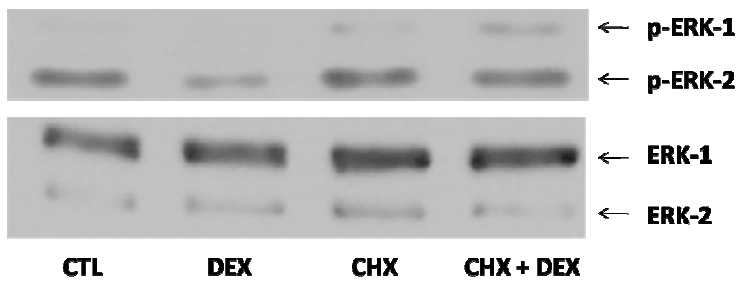

CTL DEX CHX CHX + DEX

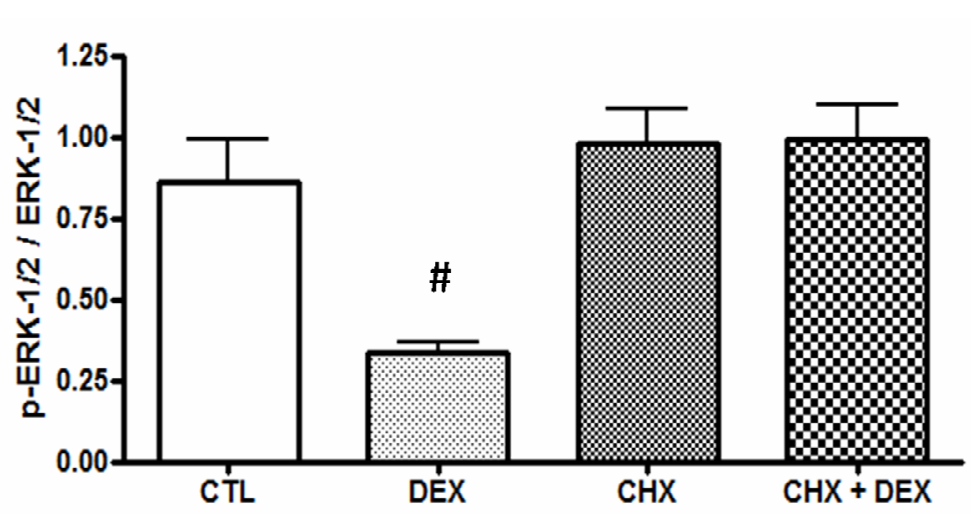

Figura 9. Fosforilação em tirosina de ERK-1/2. Células RINm5f pré-tratadas por $1 \mathrm{~h}$ com CHX (40 $\mu \mathrm{g} / \mathrm{mL})$ e posteriormente com DEX (100 nM) por $6 \mathrm{~h}$. (A) immunoblotting com anticorpo anti p-ERK-1/2 (Tyr). (B) immunoblotting com anticorpo anti ERK-1/2. (C) Gráfico da razão dos valores das densitometrias ópticas obtidas em A e B (p-ERK-1/2 / ERK-1/2). \# $p<0,05$ vs. CTL. $(\mathrm{N}=5)$.

O próximo passo foi analisar as alterações na fosforilação das ERK-1/2 induzida por DEX mediante pré-tratamento com um inibidor farmacológico das fosfatases em tirosina, ortovanadato de sódio $\left(\mathrm{VO}_{4}\right)$. Para tal, as células foram tratadas previamente com $\mathrm{VO}_{4}$ para depois serem tratadas por $6 \mathrm{~h}$ com $100 \mathrm{nM}$ de DEX. A seguir, foi feita a extração de proteínas, realização do blotting e detecção das bandas relativas às proteínas ERK-1/2, ERK-1/2 fosforiladas, MKP-1 e $\beta$-actina nas membranas de nitrocelulose.

Inicialmente, o pré tratamento com $\mathrm{VO}_{4}$ foi realizado por 30 min em concentração de $1 \mu \mathrm{M} . \mathrm{O} \mathrm{VO}_{4}$ não alterou o efeito de redução da fosforilação das ERK-1/2 induzido pela DEX (figura 10). 

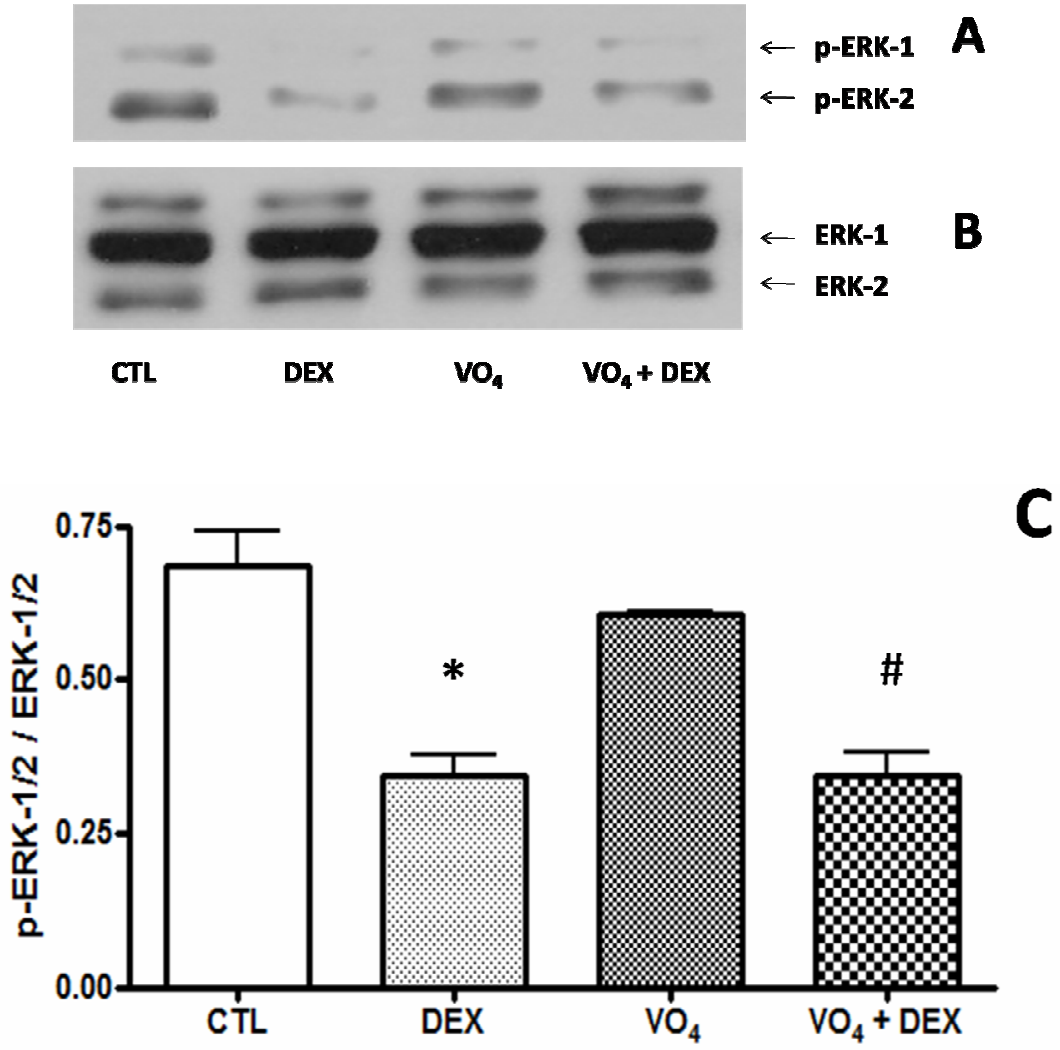

Figura 10. Fosforilação em tirosina de ERK-1/2. Células RINm5f pré-tratadas por 30 min com $\mathrm{VO}_{4}(1 \mu \mathrm{M})$ e posteriormente com DEX (100 nM) por $6 \mathrm{~h}$. (A) immunoblotting com anticorpo anti p-ERK-1/2 Tyr. (B) immunoblotting com anticorpo anti ERK-1/2. (C) Gráfico da razão dos valores das densitometrias ópticas obtidas em A e B (p-ERK-1/2 / ERK-1/2). $* p<0,01$; \# $p<0,05$ vs. CTL. (N $=3$ a 6 ).

Nas condições supracitadas, não houve interferência do $\mathrm{VO}_{4}$ na modulação da fosforilação das ERK-1/2 mediada por DEX, assim aumentou-se a concentração e o tempo de pré tratamento com o inibidor. Foi realizado, então, um pré-tratamento por $1 \mathrm{~h}$ com $\mathrm{VO}_{4} \mathrm{na}$ concentração de 1,5 $\mu \mathrm{M}$. Observou-se reversão do efeito da DEX nestas novas condições de pré-tratamento (figura 11). 

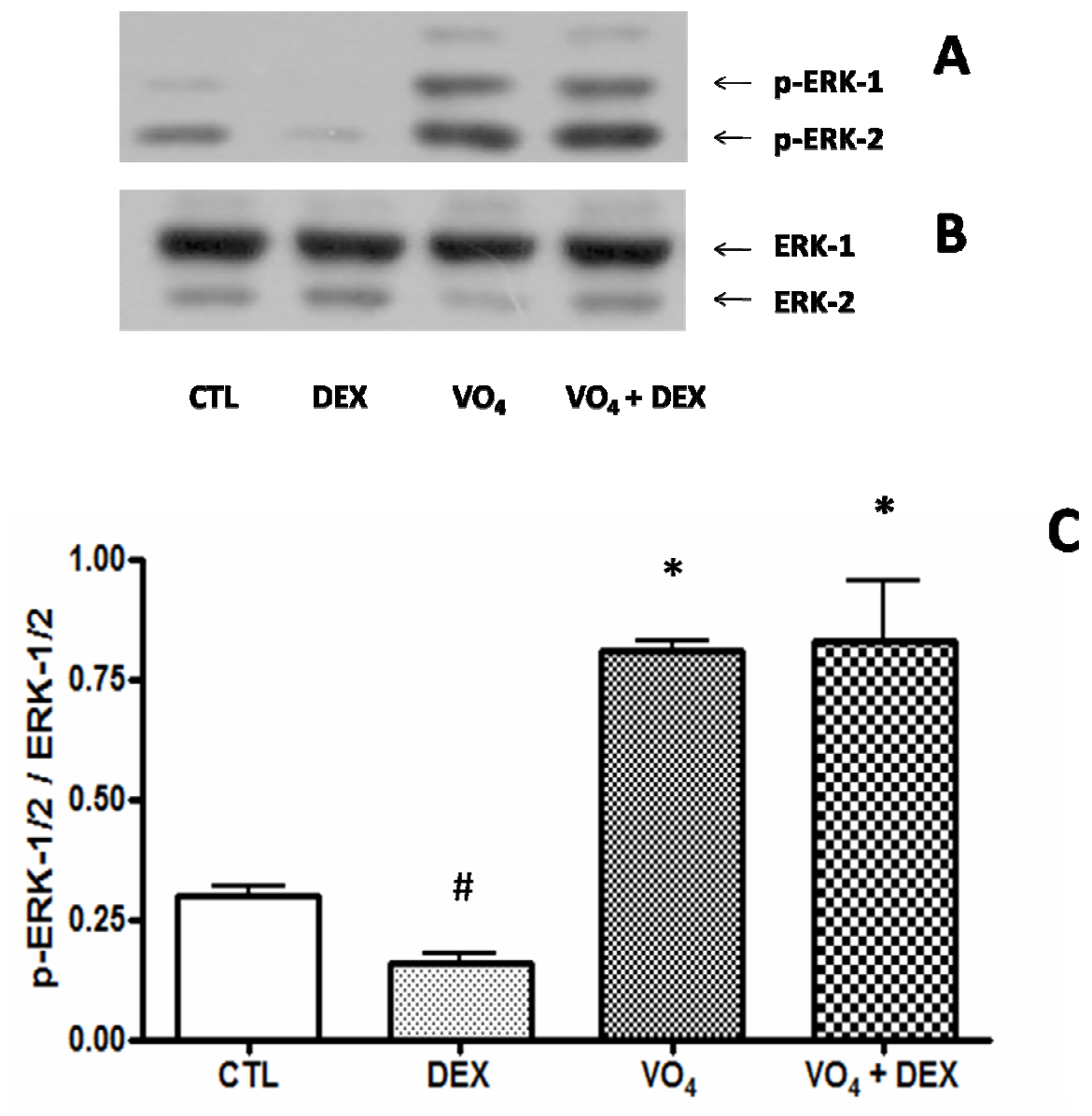

Figura 11. Fosforilação em tirosina de ERK-1/2. Células RINm5f pré-tratadas por $1 \mathrm{~h}$ com $\mathrm{VO}_{4}(1,5 \mu \mathrm{M})$ e posteriormente com DEX (100 nM) por $6 \mathrm{~h}$. (A) immunoblotting com anticorpo anti p-ERK-1/2 Tyr. (B) immunoblotting com anticorpo anti ERK-1/2. (C) Gráfico da razão dos valores das densitometrias ópticas obtidas em A e B (p-ERK-1/2 / ERK-1/2). \# $p<0,05 v s$. * $p<0,01$ vs. CTL. $(\mathrm{N}=3$ a 6$)$.

Não houve efeito do pré tratamento na expressão de nenhuma das fosfatases estudadas (figuras 12 e 13). 


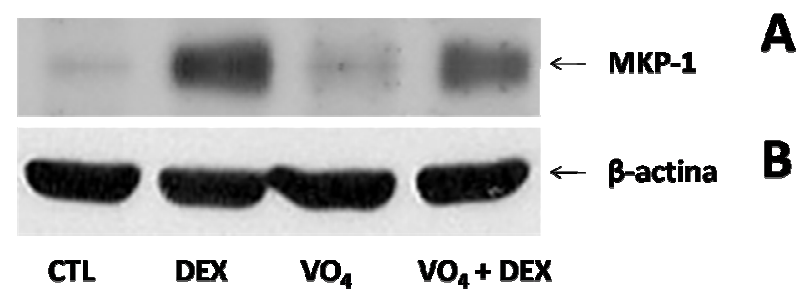

C

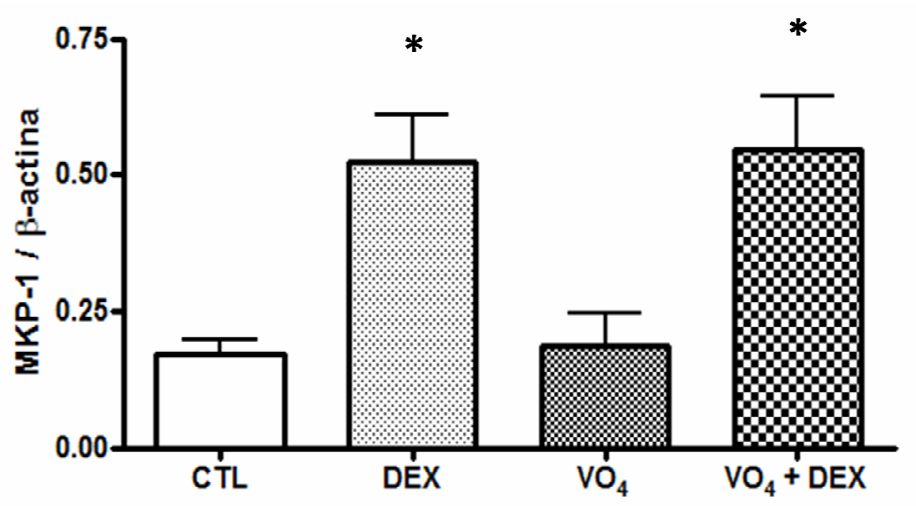

Figura 12. Expressão da fosfatase MKP-1. Células RINm5f pré-tratadas por $1 \mathrm{~h}$ com $\mathrm{VO}_{4}(1,5 \mu \mathrm{M})$ e posteriormente com DEX (100 nM) por $6 \mathrm{~h}$. (A) immunoblotting com anticorpo anti MKP-1. (B) immunoblotting com anticorpo anti $\beta$-actina. (C) Gráfico da razão dos valores das densitometrias ópticas obtidas em A e B (MKP-1 / $\beta$-actina). * $p<0,01$ vs. CTL. $(\mathrm{N}=6)$. 

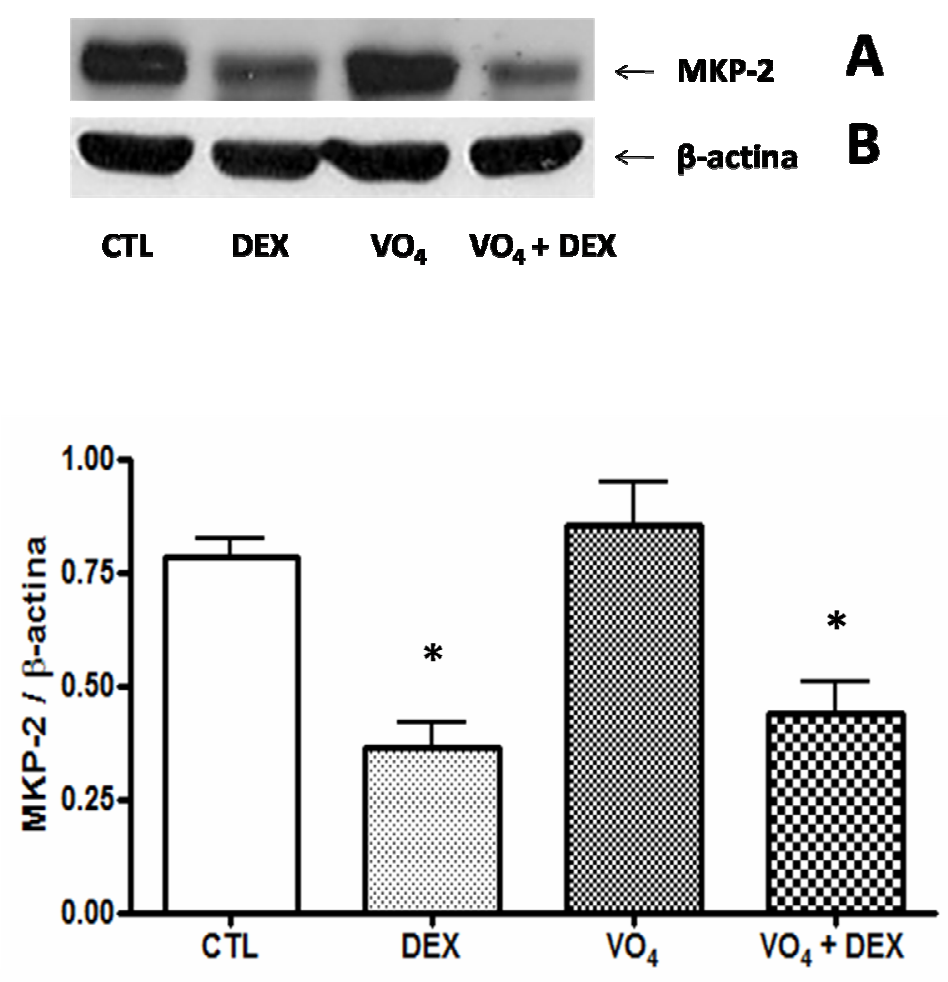

Figura 13. Expressão da fosfatase MKP-2. Células RINm5f pré-tratadas por $1 \mathrm{~h}$ com $\mathrm{VO}_{4}(1,5 \mu \mathrm{M})$ e posteriormente com DEX (100 $\mathrm{nM})$ por $6 \mathrm{~h}$. (A) immunoblotting com anticorpo anti MKP-2. (B) immunoblotting com anticorpo anti $\beta$-actina. (C) Gráfico da razão dos valores das densitometrias ópticas obtidas em A e B (MKP-2 / $\beta$-actina). * $p<0,01$ vs. CTL. $(\mathrm{N}=6)$.

\subsection{Verificação da modulação da fosforilação das proteínas ERK-1/2 após tratamento de} células MIN6 com dexametasona

Os experimentos realizados em linhagem de células beta tumoral de ratos foram repetidos em uma outra linhagem proveniente de insulinoma de camundongos, as células MIN6. Esta linhagem apresenta padrão de secreção de insulina induzido por glicose que se assemelha ao padrão fisiológico, o que as tornam um modelo experiental mais semelhante à célula beta (MIYAZAKI et al., 1990; MCCLENAGHAN; FLATT, 1999). Assim, nas células MIN6, as ERK-1/2 apresentaram redução de fosforilação quando tratadas com DEX (100 nM) de maneira similar às células RINm5f (figura 14). 

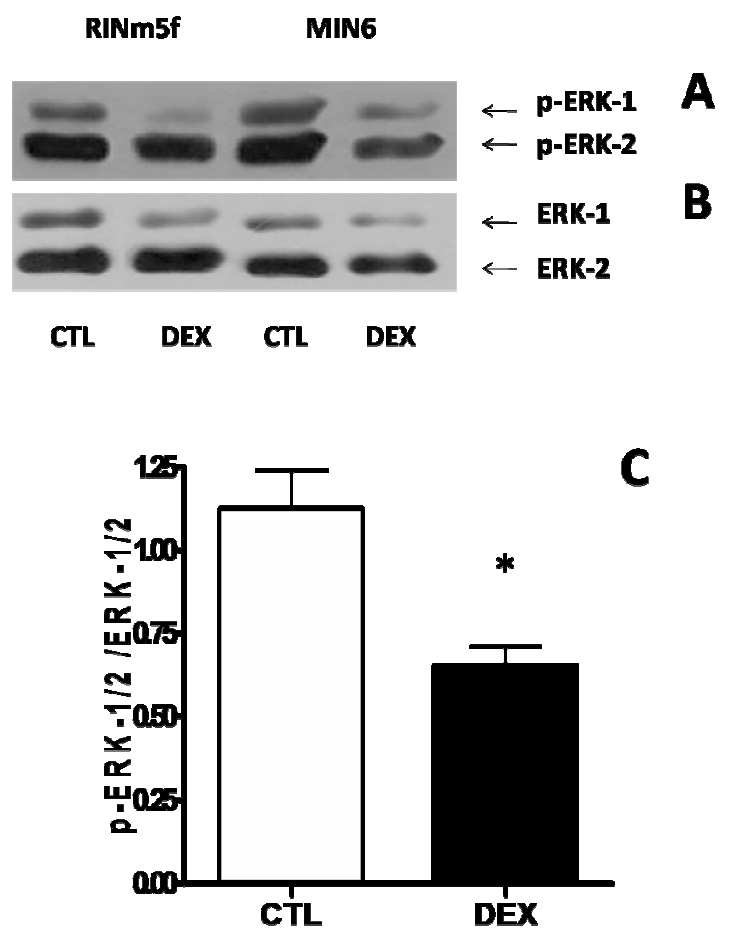

Figura 14. Fosforilação em tirosina das ERK-1/2. Células RINm5f e MIN6 tratadas com DEX (100 nM) por 6 h. (A) immunoblotting com anticorpo anti p-ERK1/2. (B) immunoblotting com anticorpo anti ERK1/2. (C) Gráfico da razão dos valores das densitometrias ópticas obtidas da fosforilação das ERK1/2 tyr em MIN6 e expressão das ERK-1/2 em MIN6 (p-ERK-1/2 / ERK-1/2). * $p<0,05$ vs. CTL. (N = $6)$.

Para os mesmos períodos de tratamentos e concentração de DEX, foi verificada a expressão das fosfatases MKP-1 (figura 15) e MKP-2 (figura 16) nas células MIN6. 

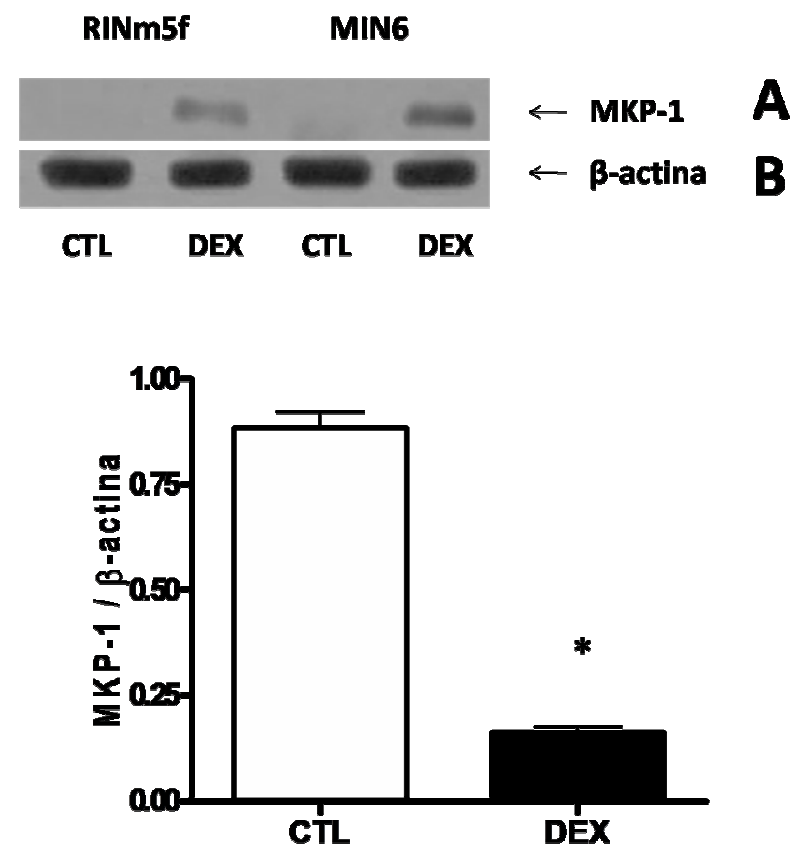

Figura 15. Expressão de MKP-1. Células RINm5f e MIN6 tratadas com DEX (100 $\eta \mathrm{M})$ por 6 h. (A) immunoblotting com anticorpo anti MKP-1. B) immunoblotting com anticorpo anti $\beta$-actina. (C) Gráfico da razão dos valores das densitometrias ópticas obtidas de MKP-1 em MIN6 e $\beta$-actina em MIN6 (MKP-1 / $\beta$-actina). * $p<0,05$ vs. CTL. $(\mathrm{N}=6)$.
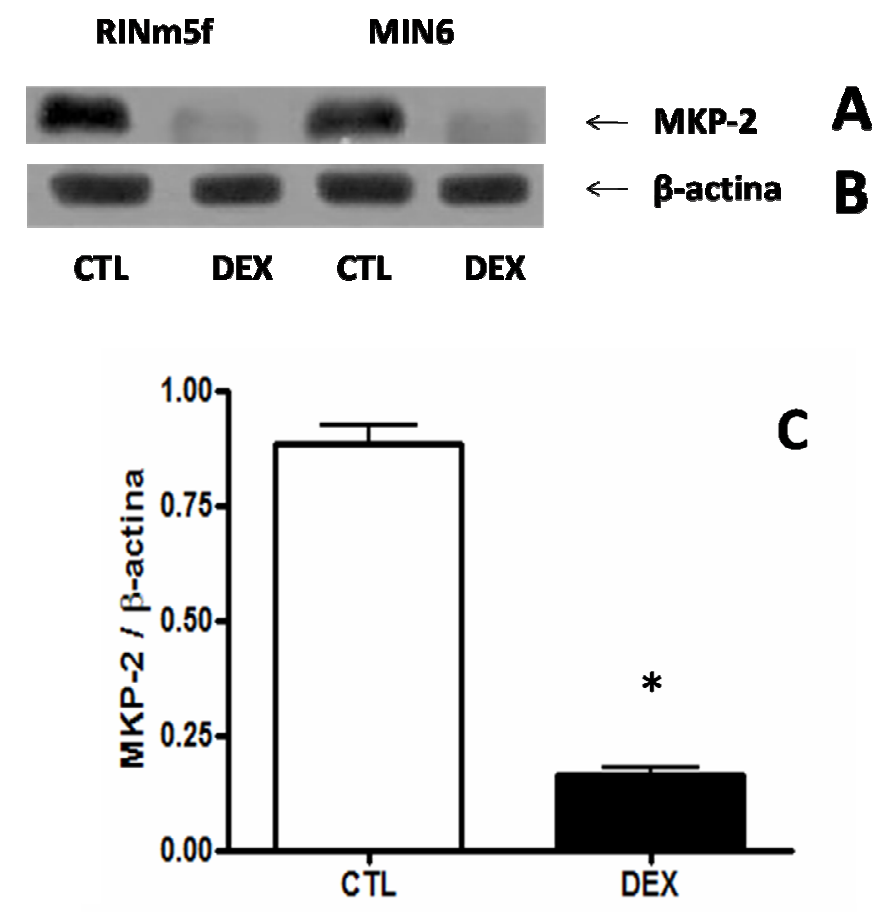

Figura 16. Expressão de MKP-2. Células RINm5f e MIN6 tratadas com DEX (100 nM) por 6 h. (A) immunoblotting com anticorpo anti MKP-2. B) immunoblotting com anticorpo anti $\beta$-actina. (C) Gráfico da razão dos valores das densitometrias ópticas obtidas de MKP-2 em MIN6 e $\beta$-actina em MIN6 (MKP-1 / $\beta$ actina). $* p<0,05 v s$. CTL. $(\mathrm{N}=6)$. 
Os efeitos de DEX na fosforilação das ERK-1/2 e expressão das fosfatases MKP-1 e MKP-2 observados nas células RINm5F foram reproduzidos nas células MIN6.

\subsection{Modulação da fosforilação das ERK-1/2 em células MIN6 com o bloqueio da} atividade de fosfatases

Verificou-se, então, que as células MIN6 respondiam ao tratamento com DEX de forma semelhante às células RINm5F. Assim, passou-se a verificar o efeito do tratamento das células MIN6 com DEX quando eram previamente tratadas com o inibidor de fosfatases ortovanadato de sódio (figura 17).
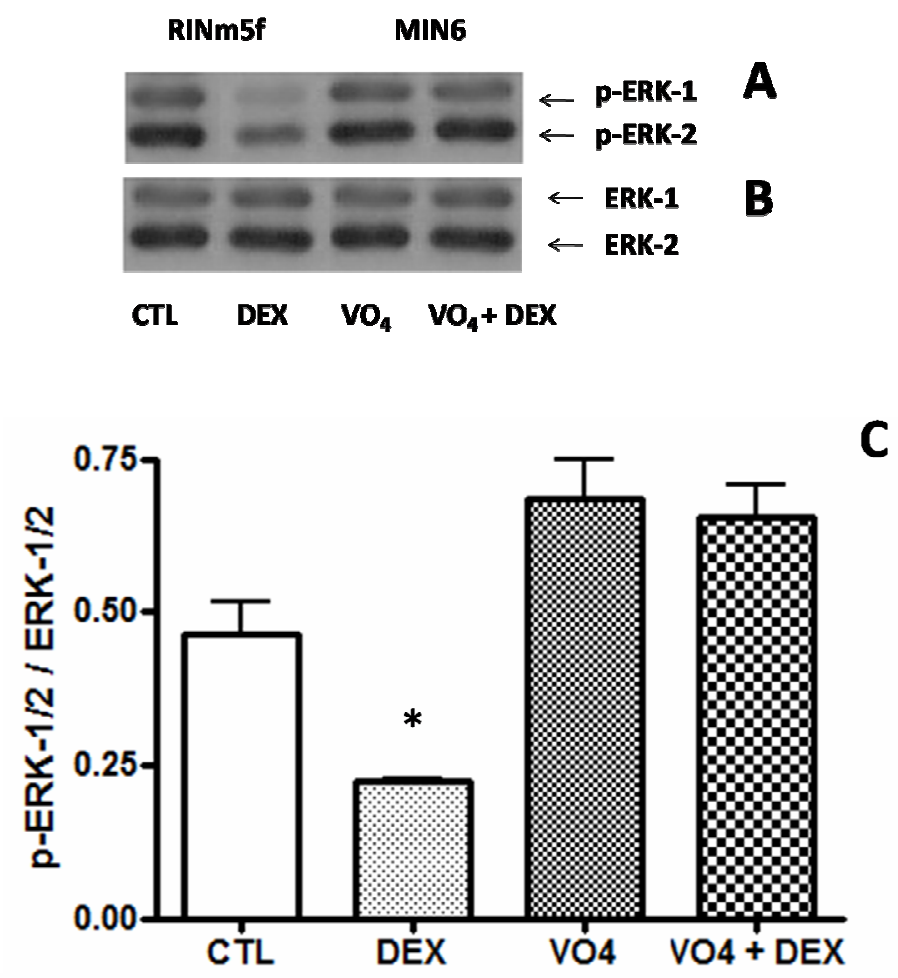

Figura 17. Fosforilação em tirosina de ERK-1/2. Células MIN6 pré-tratadas por $1 \mathrm{~h}$ com $\mathrm{VO}_{4}(1,5 \mu \mathrm{M})$ e posteriormente com DEX (100 nM) por $6 \mathrm{~h}$. (A) immunoblotting com anticorpo anti p-ERK-1/2 Tyr. (B) immunoblotting com anticorpo anti ERK-1/2. (C) Gráfico da razão dos valores das densitometrias ópticas obtidas da fosforilação das ERK1/2 tyr em MIN6 e expressão das ERK-1/2 em MIN6 (p-ERK-1/2 / ERK-1/2). * $p<0,05$ vs. CTL. $(\mathrm{N}=6)$. 
Também se verificou que as células MIN6, quando pré-tratadas com $\mathrm{VO}_{4}$, deixam de apresentar redução de fosforilação das ERK-1/2 induzidas por DEX.

\subsection{Proliferação celular por incorporação de bromo deoxiuridina em células MIN6 tratadas com DEX}

No intuito de se investigar o efeito do tratamento de DEX na células MIN6, foi realizado o ensaio de captação de bromo deoxiuridina (BrdU). Assim, quanto maior incorporação de BrdU no DNA, maior era a atividade proliferativa das células analisadas.

Para estes experimentos, as células MIN6 foram tratadas com DEX (100 nM) por $72 \mathrm{~h}$. A incorporação de BrdU diminuiu nas células tratadas com DEX (figura 18).

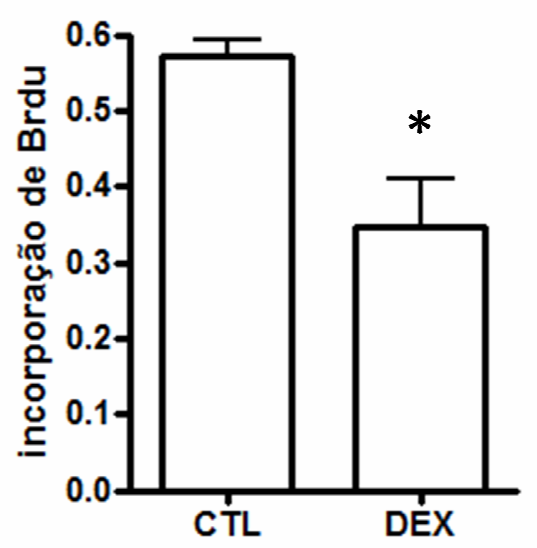

Figura 18. Incorporação de BrdU - Gráfico da absorbância de feixe de luz de comprimento de onda de 450 nm. Células MIN6 tratadas com DEX $(100 \mathrm{nM})$ por 72 h. * $p<0,05$ vs. CTL. $(\mathrm{N}=6)$.

\subsection{Bloqueio da expressão de MKP-1 nas células MIN6}

Partiu-se então para a verificação do efeito do bloqueio da expressão da fosfatase MKP-1. Assim, verificou-se a possibilidade de que o seu knockdown impedisse que houvesse diminuição da fosforilação das ERK-1/2 quando as células MIN6 eram tratadas com DEX.

As células foram transfectadas com o RNA de interferência para o gene da MKP-1 e depois tratadas com DEX (100 nM) por 6h. Após isto, realizou-se a extração de proteínas para a verificação da expressão de MKP-1 e fosforilação das ERK-1/2. Assim, foi verificado o 
êxito na inibição da expressão da proteína MKP-1 (figura 19 A) bem como a reversão do efeito de diminuição de fosforilação antes induzido pelo tratamento isolado das células MIN6 com DEX (figura 19 B).

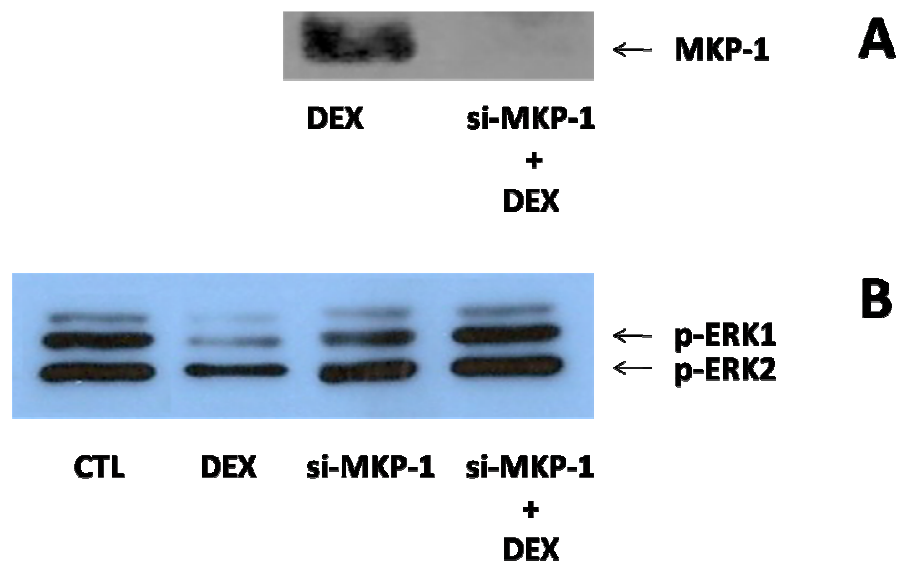

Figura 19. Expressão de MKP-1. Bloqueio da expressão de MKP-1 com utilização de RNA de interferência para o gene da MKP-1 em células MIN6 seguido de tratamento com DEX (100 nM) por 6h. (A) Immunobloting com anticorpo anti-MKP-1. (B) Immunoblotting com o anticorpo anti p-ERK-1/2 (tyr).

\subsection{Proliferação das células MIN6 tratadas com DEX com prévia inibição da expressão} de MKP-1

Uma vez comprovados, em células MIN6, a eficiência do bloqueio da expressão de MKP-1 e a dependência desta proteína para a modulação da fosforilação das ERK-1/2, partiuse para a determinação da proliferação destas células quando eram previamente transfectadas com o RNA de interferência para posterior tratamento com DEX (100 nM) por $72 \mathrm{~h}$.

As células que foram transfectadas com o RNA de interferência, quando tratadas com DEX, apresentaram atenuação do efeito de diminuição de proliferação induzido por DEX (figura 20). 


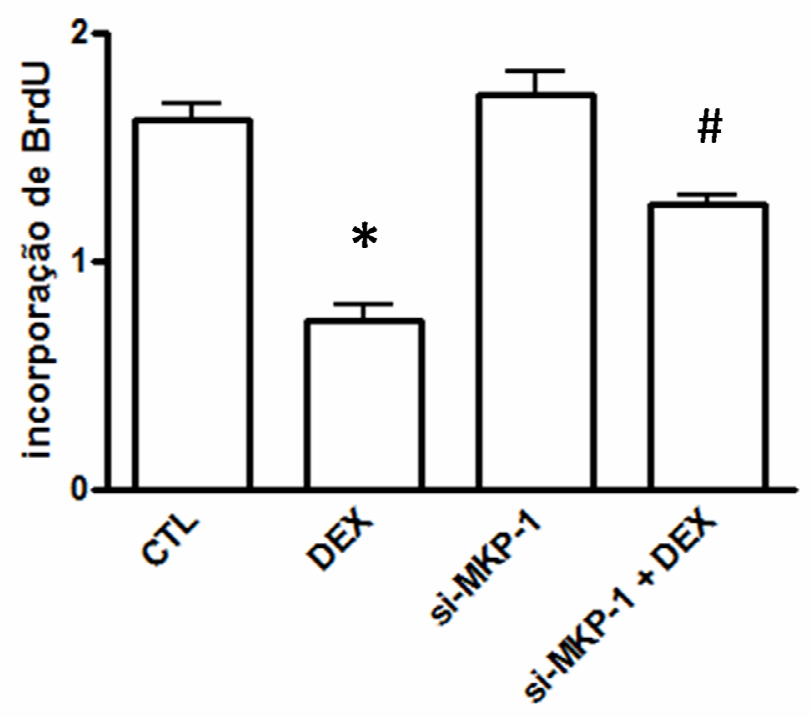

Figura 20. Incorporação de BrdU. Gráfico da absorbância de feixe de luz de comprimento de onda de $450 \mathrm{~nm}$. Células MIN6 transfectadas com si-RNA-MKP-1 e tratadas com DEX (100 nM) por $72 \mathrm{~h}$. * $p<0,05$ vs. CTL, \# $p<0,05$ vs. CTL e DEX. $(\mathrm{N}=6)$.

\subsection{Modulação da expressão de proteínas do ciclo celular em células MIN6 tratadas com DEX}

No intuito de se verificar se o glicocorticóide sintético também atua na manutenção do ciclo celular, iniciou-se a verificação da expressão de proteínas envolvidas no controle e na progressão deste ciclo.

Assim, foi realizado o tratamento das células MIN6 com DEX (100 nM) por $24 \mathrm{~h}$ e subseqüente verificação da expressão das proteínas CD1, CDK4 e p21 (figuras 21, 22 e 23). 


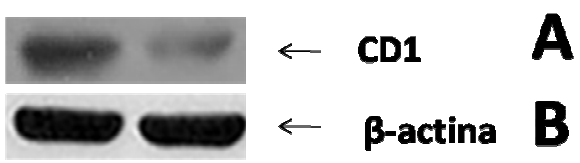

CTL DEX

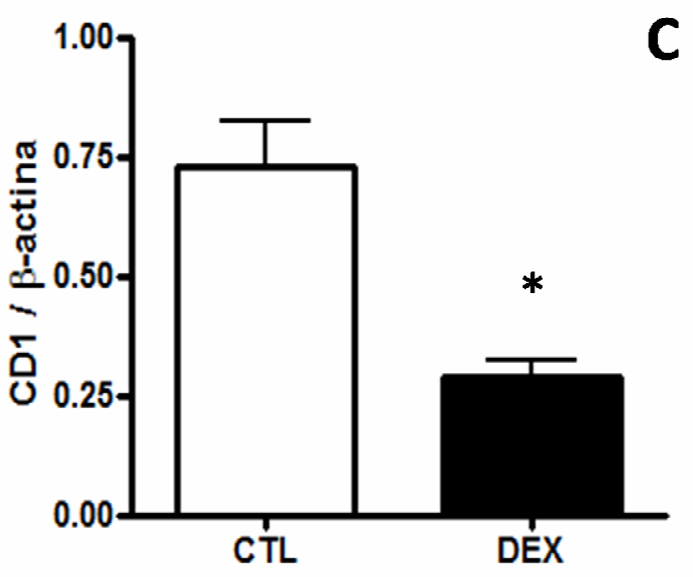

Figura 21. Expressão de CD1. Células MIN6 tratadas com DEX (100 nM) por 24 h. (A) immunoblotting com anticorpo anti CD1. (B) immunoblotting com anticorpo anti $\beta$-actina. (C) Gráfico da razão dos valores das densitometrias ópticas obtidas em A e B (CD1 / $\beta$-actina). $* p<0,05$ vs. CTL. $(\mathrm{N}=6)$.
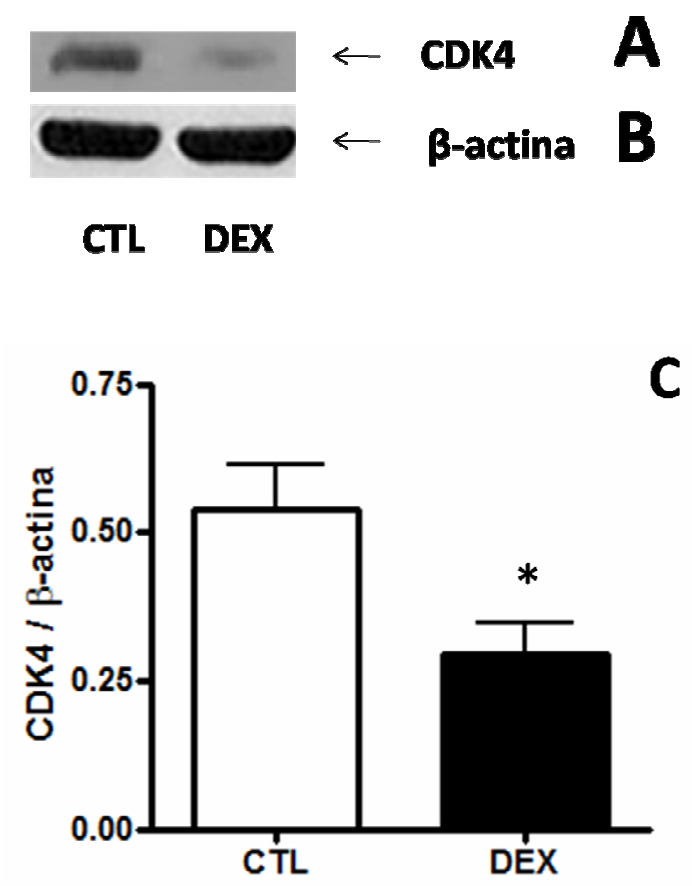

Figura 22. Expressão de CDK4. Células MIN6 tratadas com DEX (100 nM) por 24 h. (A) immunoblotting com anticorpo anti CDK4. (B) immunoblotting com anticorpo anti $\beta$-actina. (C) Gráfico da razão dos valores das densitometrias ópticas obtidas em A e B (CDK4 / $\beta$-actina). $* p<0,05$ vs. CTL. $(\mathrm{N}=6)$. 


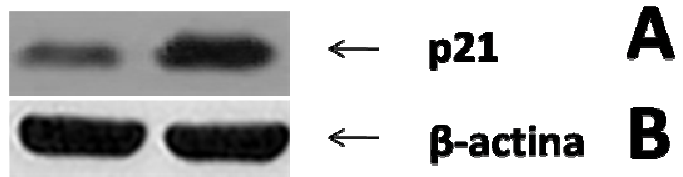

CTL DEX

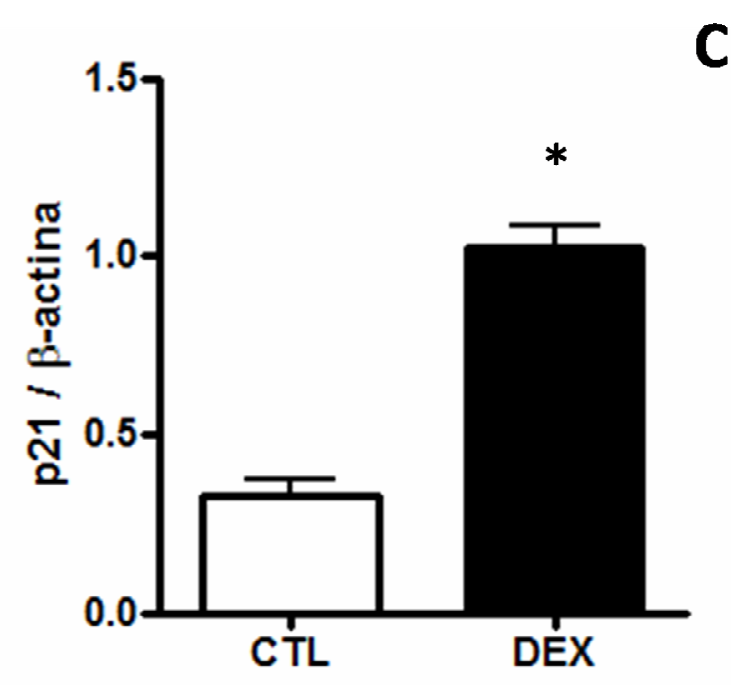

Figura 23. Expressão de p21. Células MIN6 tratadas com DEX (100 nM) por 24 h. (A) immunoblotting com anticorpo anti p21. (B) immunoblotting com anticorpo anti $\beta$-actina. (C) Gráfico da razão dos valores das densitometrias ópticas obtidas em A e B (p21 / $\beta$-actina). $* p<0,05$ vs. CTL. $(\mathrm{N}=6)$.

Verificou-se que DEX induz a expressão de p21 enquanto leva à diminuição da expressão de CD1 e CDK4. 
DISCUSSÃO 


\section{DISCUSSÃO}

Da mesma forma que a massa e atividade do pâncreas endócrino aumentam na gravidez, durante o período pós-parto esta glândula sofre modificações que levam ao retorno de sua atividade secretora, desse modo, ocorre redução da massa de células beta por processos como apoptose e diminuição de proliferação (MARYNISSEN; AERTS; VAN ASSCHE, 1983; LEE; NIELSEN, 2009). Nos estágios finais da gestação são detectadas altas concentrações de glicocorticóides circulantes, assim, acredita-se que estes sejam os responsáveis pelo efeito de diminuição de proliferação destas células (DUPOUY; COFFIGNY; MAGRE, 1975; COHEN, 1976; MARTIN, et al., 1977; WEINHAUSS et al., 2000; SHAO; QIAO; FRIEDMAN, 2004). Baseado nestas evidências, o objetivo do presente trabalho foi estudar os mecanismos moleculares envolvidos na diminuição de proliferação de células beta induzida pelos glicocorticóides.

Em nosso trabalho foram utilizadas linhagens tumorais de células beta de ratos e de camundongos. O uso de células beta primárias em pesquisas que envolvem experimentos bioquímicos e de biologia molecular muitas vezes é limitado pela indisponibilidade de quantidade suficiente de tecido pancreático endócrino dos modelos experimentais. Desse modo, ao longo das últimas décadas, diversos pesquisadores tentam desenvolver linhagens de células secretoras de insulina que mantenham a capacidade normal de secreção do hormônio. Poucas destas tentativas tem obtido êxito pelo fato de que a capacidade de proliferação muitas vezes exclui a possibilidade de serem mantidas as capacidades funcionais da célula. Em nossos estudos foram utilizadas células tumorais de camundongos MIN6 que tem a capacidade de manter a regulação normal de secreção de insulina (MIYAZAKI et al., 1990; MCCLENAGHAN; FLATT, 1999). Apesar dessas linhagens tumorais não mimetizarem perfeitamente a fisiologia das células beta primárias, elas são ferramentas extremamente 
importantes para o estudo de eventos moleculares que envolvem a função/disfunção destas células (POITOUT; OLSON; ROBERTSON, 1996). Além disso, é bastante pertinente o uso de linhagens tumorais em estudos que envolvam proliferação celular, pois se tornam mais evidentes alterações do crescimento, uma vez que nestas células a capacidade proliferativa é extremamente mais acentuada do que em linhagens primárias.

Assim, para verificação da nossa hipótese, as células MIN6 e RINm5f foram tratadas com o glicocorticóide sintético dexametasona, em concentração equivalente a dos glicocorticóides endógenos encontrada no período perinatal (WEINHAUSS et al., 2000). O ensaio de incorporação de BrdU em células MIN6 mostra que há redução da proliferação quando estas eram tratadas por $72 \mathrm{~h}$ com DEX. Este resultado evidencia a participação de glicocorticóides na remodelação do pâncreas endócrino no período pós-parto. Assim, concluise que a maneira como os glicocorticóides realizam este remodelamento estaria envolvendo a redução da proliferação celular.

A manutenção da quantidade de células nos tecidos é exercida não somente pelo controle do número de células em processos de proliferação, mas também pelo controle do número de células em processo de morte celular. Um determinado estímulo pode levar à ativação de vias intracelulares que culminam com a morte desta célula. Este mecanismo de morte celular programada e organizada é chamado de apoptose. Os glicocorticóides são conhecidos por induzirem a morte de células por apoptose em diferentes tecidos como músculo (OSHIMA et al., 2004), células ósseas (LIU et al., 2004), timócitos (PURTON et al., 2004), células linfóides (MALONE; WANG; DISTELHORST, 2004), condrócitos (CHRYSIS et al., 2005) e células de mieloma (FRANKFURT; ROSEN, 2004).

Ranta e colaboradores (2006) demonstraram que a dexametasona induz a morte de células beta tumorais INS-1 por apoptose através da redução da expressão da proteína antiapoptótica Bcl-2 e desfosforilação da proteína BAD. Estes dados indicam que a 
dexametasona ativa a via intrínseca da apoptose. A ativação desse mecanismo ocorre quando há perda da integridade da membrana mitocondrial, desencadeada por alterações da quantidade de proteínas cruciais para a manutenção de sua estabilidade (LIU et al., 1996).

Ao contrário da existência de trabalhos buscam avaliar os mecanismos envolvidos na atividade da apoptótica induzida pelos glicocorticóides, há poucos estudos que ponderam sobre os mecanismos anti-proliferativo destes, principalmente em células beta. Desse modo nossos trabalhos foram focados somente na verificação da atividade proliferativa induzida pelos glicocorticóides. Assim, a atividade anti-proliferativa de DEX já foi relatada em linhagem de osteoblastos humanos e de camundongos, (ENGELBRECHT et al., 2003; HORSH et al., 2007) porém não havia sido mostrado que a DEX induz a diminuição da proliferação de células beta.

No estudo de vias de sinalização nas quais estão envolvidas proteínas cuja função esteja relacionada ao controle de proliferação, destacam-se as ERK-1/2. Estas proteínas têm importante função no controle de sobrevida de diversos tipos celulares inclusive de células beta (LEWIS; SHAPIRO; AHN, 1998; PEARSON et al., 2001; JOHNSON; LAPADAT, 2002; YOON; SEGER, 2006; LINGOHR et al., 2002; PARASKEVAS et al., 1999; PETERSEN et al., 2002). A atividade das ERK-1/2 é decorrente de fosforilações em sua molécula, desse modo, fosfatases estão intimamente relacionadas ao controle de sua atividade.

Em nosso trabalho, verificamos que nas células RINm5F e nas células MIN6 o tratamento com DEX por $6 \mathrm{~h}$ com $100 \mathrm{nM}$ levou ao concomitante aumento da expressão da fosfatase MKP-1 e diminuição de fosforilação das ERK-1/2. O padrão de fosforilação das ERK-1/2 observado no tratamento com glicocorticóide é também corroborado pelos resultados obtidos em linhagem de mastócitos, RBL-2H3, onde foi visto que a fosforilação da ERK-2 era diminuída em tratamento por 6 h com 100 nM de DEX (RIDER et al., 1996). Resultados semelhantes foram observados em outro trabalho também envolvendo linhagem 
de mastócitos, onde o tratamento com DEX aumentou a expressão de MKP-1 e inativação das ERK-1/2 (KASSEL et al., 2001).

A partir do momento que os resultados obtidos sugeriam que a dexametasona diminuía a atividade das ERK-1/2 através da regulação da expressão de fosfatases, partimos para a verificação da inibição da síntese protéica e atividade das fosfatases previamente ao tratamento das células com DEX. O tratamento prévio com $\mathrm{CHX}$, um inibidor da síntese protéica, impediu o aumento da expressão de MKP-1 anteriormente verificado no tratamento com DEX e, concomitantemente, impediu a diminuição da fosforilação das ERK-1/2. Também não foi mais verificada a diminuição da fosforilação das ERK-1/2 induzida por DEX quando as células eram previamente tratadas com um inibidor de fosfatases, ortovanadato de sódio.

Em conjunto, estes resultados evideciam a participação de fosfatases reguladas por genes de expressão imediata no mecanismo de desfosforilação das ERK-1/2 induzido por DEX. É muito provável a participação da MKP-1 neste mecanismo, uma vez que já foi observado, em linhagem de pre-osteoblasto de humano (MG-63), que a diminuição da fosforilação das ERK-1/2 induzida por DEX era revertida quando as células eram submetidas a tratamento com RNA de interferência (siRNA) para a MKP-1 (HORSH et al., 2007). Estes dados corroboram nossos resultados pois verificamos que DEX induz um aumento da espressão da MKP-1 com coincidente redução da fosforilação da ERK-1/2.

Verificamos também que houve diminuição da expressão da fosfatase MKP-2 nas células tratadas com DEX. Esta fosfatase, apesar de já ter sido descrita como enzima desfosforiladora das proteína ERK-1/2 em alguns tipos celulares, não tem esta atividade comprovada em células beta. Além disso, o fato de que a expressão de MKP-2 era inibida com o tratamento com DEX torna remota a possibilidade desta fosfatase contribuir 
significativamente com a desfosforilação das ERK-1/2, uma vez que ocorre concomitante redução de sua expressão e diminuição da fosforilação das ERK-1/2.

Sendo assim partiu-se para a verificação do efeito do bloqueio da expressão da MKP-1 nas células MIN6 tratadas com DEX. Foi realizado, então, o tratamento das células com o RNA de interferência para o silenciamento do gene da proteína MKP-1. Inicialmente verificou-se que a inibição da expressão de MKP-1 foi eficiente em impedir a diminuição da fosforilação das ERK-1/2 induzida por DEX. Finalmente, no teste de captação de BrdU, verificou-se que as células MIN6 tratadas com o si-RNA não apresentavam a mesma diminuição de proliferação de quando eram tratadas com DEX.

Nossos resultados evidenciam, pela primeira vez, um mecanismo pelo qual o glicocorticóide sintético leva a diminuição da proliferação de células beta. Assim, DEX induz rapidamente a expressão de uma fosfatase, MKP-1, a qual atua diminuindo a fosforilação e consequentemente a atividade das ERK-1/2 que, por sua vez, diminui parcialmente, ao longo do tempo, a capacidade celular de proliferação.

O mecanismo estudado ajuda a elucidar o processo fisiológico envolvido no remodelamento do pâncreas endócrino no periparto, uma vez que há evidências de que o retorno da massa das células beta ao estado em que se encontrava anteriormente à gravidez seja dependente da atividade dos glicocorticóides circulantes. Essa proposta é corroborada por um trabalho no qual osteoblastos apresentavam diminuição de proliferação quando tratados por DEX (HORSH et al., 2007). O mecanismo envolvido nesta regulação é o mesmo evidenciado por nossos resultados.

Sabe-se que a massa de células beta é regulada por diversos processos como diferenciação celular, neogênese, aumento ou diminuição da massa da célula, morte celular por apoptose e proliferação celular (NIELSEN et al., 2001; NIELSEN et al., 1999; SCAGLIA; SMITH; BONNER-WEIR, 1995; SCAGLIA et al., 1997; FINEGOOD et al., 
1997; COZAR-CASTELLANO et al., 2006a; LEE; NIELSEN, 2009). No intuito de se verificar se o glicocorticóide sintético também atua na manutenção do ciclo celular, foi realizada, em paralelo ao mecanismo de proliferação estudado, a análise da expressão de proteínas envolvidas no controle e na progressão deste ciclo.

A replicação celular é regulada pelo preciso controle na entrada, passagem e saída do ciclo celular. Esta série de eventos é iniciada pela formação de complexos entre as ciclinas (ciclinas do tipo D - CD) e cinases dependentes de ciclinas (CDK). A associação das CD com as CDK induzem fosforilação e consequente desativação da proteína de retinoblastoma (pRb). Esta proteína, quando ativada (desfosforilada) leva à repressão transcricional de genes envolvidos na progressão do ciclo celular, assim, quando desativada induz estímulos mitogênicos em diferentes tecidos por promover a progressão do ciclo celular (GÉRARD; GOLDBETER, 2009).

Na célula beta, as proteínas CD1 e CDK4 têm sido mostradas com importante função no controle do ciclo celular. Ilhotas de ratos e humanos que apresentavam aumento de expressão de CD1 e CDK4 pela utilização de adenovírus tiveram maior de proliferação juntamente com aumento da fosforilação de pRb (COZAR-CASTELLANO et al., 2004).

A proteína $\mathrm{p} 21^{\text {cip1 }}$ pertence ao grupo de proteínas denominado CIP/KIP CDK inhibitors family que se associam ao complexo CD-CDK, limitando a progressão do ciclo celular. Foi verificado que ilhotas isoladas de camundongos com deleção de p21 são mais responsivas a fatores de crescimento do que ilhotas normais (COZAR-CASTELLANO et al., 2006b), sugerindo que esta proteína exerce, então, uma função de controle sobre a proliferação da célula beta pancreática.

Nossos experimentos mostram que DEX induz a expressão de p21 enquanto leva à diminuição da expressão de CD1 e CDK4. Estes resultados também reforçam, por outro 
mecanismo, a contribuição dos glicocorticóides para a diminuição da proliferação das células beta. 
CONCLUSÕES 


\section{CONCLUSÕES}

Os resultados de nosso estudo demonstram que a dexametasona reduz a proliferação das células beta da linhagem MIN6. O mecanismo molecular envolve o aumento da expressão da fosfatase MKP-1 que, por sua vez, induz diminuição da fosforilação das proteínas ERK$1 / 2$.

Além disso, DEX regula a expressão de proteínas envolvidas no controle do ciclo celular, induzindo (1) a diminuição da expressão de CDK4 e CD1, proteínas relacionadas com o controle da progressão do ciclo celular, e (2) o aumento da expressão da proteína p21, envolvida com o bloqueio da progressão do ciclo celular.

Em conjunto, esses dados evidenciam a participação dos glicocorticóides no processo de remodelamento do pâncreas endócrino durante o período compreendido entre o final da gravidez e o início da lactação.

Os resultados obtidos nesse trabalho fornecem informações acerca dos mecanismos envolvidos na manutenção da viabilidade de células beta pancreáticas. Estas informações se unem aos inúmeros trabalhos realizados com o intuito de contribuir com o acúmulo de conhecimento voltado para o desenvolvimento de técnicas para a prevenção e tratamento de doenças relacionadas à secreção de insulina. 


\section{REFERÊNCIAS}




\section{REFERÊNCIAS*}

AMARAL, M. E.; UENO, M.; CARVALHEIRA, J. B.; CARNEIRO, E. M.; VELLOSO, L. A.; SAAD, M. J.; BOSCHERO, A. C. Prolactin-signal transduction in neonatal rat pancreatic islets and interaction with the insulin-signaling pathway. Horm. Metab. Res., v. 35, p. 282289, 2003.

ANHE, G. F. Adaptações coordenadas da função do pâncreas endócrino e da ação da insulina em músculo esquelético contribuem para a regulação da homeostasia glicêmica no período perinatal. 2007. 103 f. Tese (Doutorado em Fisiologia Humana) - Instituto de Ciências Biomédicas, Universidade de São Paulo, 2007.

BENDER, H. S.; CHICKERING, W. R. Pregnancy and diabetes: the maternal response. Life Sci., v. 37, p. 1-9, 1985.

BORDIN, S.; AMARAL, M. E.; ANHE, G. F.; DELGHINGARO-AUGUSTO, V.; CUNHA, D. A.; NICOLETTI-CARVALHO, J. E.; BOSCHERO, A. C. Prolactin-modulated gene expression profiles in pancreatic islets from adult female rats. Mol. Cell. Endocrinol., v. 220, p. 41-50, 2004.

BRAUNSCHWEIGER, P. G.; STRAGAND, J. J.; SCHIFFER, L. M. Effect of methylprednisolone on cell proliferation in $\mathrm{C} 3 \mathrm{H} / \mathrm{HeJ}$ spontaneous mammary tumors. Cancer Res., v. 38, p. 4510-454, 1978.

BRELJE, T. C.; SORENSON, R. L. Role of prolactin versus growth hormone on islet B-cell proliferation in vitro: implications for pregnancy. Endocrinology., v. 128, p. 45-57, 1991.

CAMPS, M.; NICHOLS, A.; ARKINSTALL, S. Dual specificity phosphatases: a gene family for control of MAP kinase function. FASEB J., v. 14, p. 6-16, 2006.

CHA, H. H.; CRAM, E. J.; WANG, E. C.; HUANG, A.J.; KASLER, H. G.; FIRESTONE, G. L. Glucocorticoids stimulate p21 gene expression by targeting multiple transcriptional elements within a steroid responsive region of the $\mathrm{p} 21$ waf1/cip1 promoter in rat hepatoma cells. J. Biol. Chem., v. 273, p. 1998-2007, 1998.

CHARLES, C. H.; ABLER, A. S.; LAU, L. F. cDNA sequence of a growth factor-inducible immediate early gene and characterization of its encoded protein. Oncogene, v. 7, p. 187-190, 1992. 
*De acordo com Associação Brasileira de Normas Técnicas. NBR 6023: Informação e documentação: referências: elaboração. Rio de Janeiro, 2002.

CHEN, P.; LI, J.; BARNES, J.; KOKKONEN, G. C.; LEE, J. C.; LIU, Y. Restraint of proinflammatory cytokine biosynthesis by mitogen-activated protein kinase phosphatase- 1 in lipopolysaccharide-stimulated macrophages. J. Immunol., v. 169, p. 6408-6416, 2002.

CHOI, S. E.; CHOI, K. M.; YOON, I. H.; SHIN, J. Y.; KIM, J. S.; PARK, W. Y; HAN, D. J.; KIM, S. C.; AHN, C.; KIM, J. Y.; HWANG, E. S.; CHA, C. Y.; SZOT, G. L.; YOON, K. H.; PARK, C. G. IL-6 protects pancreatic islet beta cells from pro-inflammatory cytokinesinduced cell death and functional impairment in vitro and in vivo. Transpl. Immunol., v. 13, p. 45-53, 2004.

CHRYSIS, D.; ZAMAN, F.; CHAGIN, A. S.; TAKIGAWA, M.; SAVENDAHL, L. Dexamethasone induces apoptosis in proliferative chondrocytes through activation of caspases and suppression of the Akt-phosphatidylinositol 3_-kinase signaling pathway. Endocrinology., v. 46, p. 1391-1397, 2005.

COHEN, A. Adrenal and plasma corticosterone levels in the pregnant, fetal and neonatal rat, in the perinatal period. Horm. Metab. Res., v. 8, p. 474-47, 1976.

COZAR-CASTELLANO, I.; FIASCHI-TAESCH, N.; BIGATEL, T. A.; TAKANE, K. K.; GARCIA-OCANA, A.; VASAVADA, R.; STEWART, A. Molecular control of cell cycle progression in the pancreatic beta-cell. Endocr. Rev., v. 27, p. 356-370, 2006.

COZAR-CASTELLANO, I.; TAKANE, K. K.; BOTTINO, R.; BALAMURUGAN, A. N.; STEWART, A. F. Induction of beta-cell proliferation and retinoblastoma protein phosphorylation in rat and human islets using adenovirus-mediated transfer of cyclindependent kinase-4 and cyclin D1. Diabetes, v. 53, p. 149-159, 2004.

COZAR-CASTELLANO I, WEINSTOCK M, HAUGHT M, VELÁZQUEZ-GARCIA S, SIPULA D, STEWART AF. Evaluation of beta-cell replication in mice transgenic for hepatocyte growth factor and placental lactogen: comprehensive characterization of the G1/S regulatory proteins reveals unique involvement of p21cip. Diabetes, v. 55, p.70-77, 2006.

DICKINSON, R. J.; KEYSE, S. M. Diverse physiological functions for dual-specificity MAP kinase phosphatases. J. Cell. Sci., v. 119, p. 4607-4615, 2006.

DUPOUY, J. P.; COFFIGNY, H.; MAGRE, S. Maternal and fetal corticosterone levels during late pregnancy in rats. J. Endocrinol., v. 65, p. 347-352, 1975. 
EBISUYA, M.; KONDOH, K.; NISHIDA, E. The duration, magnitude and compartmentalization of ERK MAP kinase activity: mechanisms for providing signaling specificity. J. Cell. Sci., v. 118, p. 2997-3002, 2005.

ENGELBRECHT, Y.; DE WET, H.; HORSCH. K.; LANGEVELDT, C. R.; HOUGH, F. S.; HULLEY, P. A. Glucocorticoids induce rapid up-regulation of mitogen-activated protein kinase phosphatase-1 and dephosphorylation of extracellular signal-regulated kinase and impair proliferation in human and mouse osteoblast cell lines. Endocrinology., v. 144, p. 412422, 2003.

FÉLIX, M. A.; LABBÉ, J. C.; DORÉE, M.; HUNT, T.; KARSENTI, E. Triggering of cyclin degradation in interphase extracts of amphibian eggs by cdc2 kinase. Nature, v. 346, p. 379$382,1990$.

FINEGOOD, D.T.; SCAGLIA, L.; BONNER-WEIR, S. Dynamics of b-cell mass in the growing rat pancreas: estimation with a simple mathematical model. Diabetes, v. 44, p. 249256, 1995.

FRANKFURT, O.; ROSEN, S. T. Mechanisms of glucocorticoid-induced apoptosis in hematologic malignancies: updates. Curr. Opin. Oncol., v. 16, p.553-563, 2004.

GÉRARD, C.; GOLDBETER, A. Temporal self-organization of the cyclin/Cdk network driving the mammalian cell cycle. Proc. Natl. Acad. Sci., v. 106, p. 21643-21648,2009.

GOYA, L.; MAIYAR, A. C.; GE, Y.; FIRESTONE, G. L. Glucocorticoids induce a G1/G0 cell cycle arrest of Con8 rat mammary tumor cells that is synchronously reversed by steroid withdrawal or addition of transforming growth factor alpha. Mol. Endocrinol., v.7, p. 1121$1132,1993$.

HEINRICH, P. C.; BEHRMANN, I.; HAAN, S.; HERMANNS, H. M.; MÜLLER-NEWEN, G.; SHAPER, F. Principles of interleukin (IL)-6-type cytokine signaling and its regulation. Biochem. J., 374, p. 1-20, 2003.

HELLMAN, B. The islets of Langerhans in the rat during pregnancy and lactation, with special reference to the changes in the B/A cell ratio. Acta. Obstet. Gynecol. Scand., v. 39, p. 331-342, 1960.

HERR, I.; GASSLER, N.; FRIESS, H.; BUCHLER, M. W.Regulation of differential pro and anti-apoptotic signaling by glucocorticoids. Apoptosis, v. 12, p. 271-291, 2007. 
HITOMI, M.; YANG, K.; GUO, Y.; FRETTHOLD, J.; HARWALKAR, J.; STACEY, D. W. p27Kip1 and cyclin-dependent kinase 2 regulate passage through the restriction point. Cell Cycle, v. 5, p. 2281-2289, 2006.

HOCHEGGER, H.; TAKEDA, S.; HUNT, T. Cyclin-dependent kinases and cell-cycle transitions: Does one fit all? Nat. Rev. Mol. Cell. Biol., v. 9, p. 910-916, 2008.

HORNNES, P. J. On the decrease of glucose tolerance in pregnancy. A review. Diabetes Metab., v. 11, p. 310-315, 1985.

HORSCH, K.; DE WET, H.; SCHUURMANS, M. M.; ALLIE-REID, F.; CATO, A. C.; CUNNINGHAM, J.; BURRIN, J. M.; HOUGH, F. S.; HULLEY, P. A. Mitogen-activated protein kinase phosphatase 1/dual specificity phosphatase 1 mediates glucocorticoid inhibition of osteoblast proliferation. Mol. Endocrinol., v. 21, p. 2929-2940, 2007.

HUISING, M. O.; VAN DER MEULEN, T.; VAUGHAN, J. M.; MATSUMOTO, M.; DONALDSON, C. J.; PARK, H.; BILLESTRUP, N.; VALE, W. W. CRFR1 is expressed on pancreatic beta cells, promotes beta cell proliferation, and potentiates insulin secretion in a glucose-dependent manner. Proc. Natl. Acad. Sci., v. 107, p. 912-917, 2010.

JOHNSON, G. L.; LAPADAT, R.; Mitogen-activated protein kinase pathways mediated by ERK, JNK, and p38 protein kinases. Science, v. 298, p. 1911-1912, 2002.

KASSEL, O.; SANCONO, A.; KRATZSCHMAR, J.; KREFT, B.; STASSEN, M.; CATO, A. C. Glucocorticoids inhibit MAP kinase via increased expression and decreased degradation of MKP-1. EMBO J., v. 20, p. 7108-7116, 2001.

KAWAI, M.; KISHI, K. Adaptation of pancreatic islet B-cells during the last third of pregnancy: regulation of B-cell function and proliferation by lactogenic hormones in rats. Eur. J. Endocrinol., v. 141, p. 419-425, 1999.

KEYSE, S. M. Protein phosphatases and the regulation of mitogen-activated protein kinase signaling. Curr. Opin. Cell Biol., v. 12, p. 186-192, 2000.

KONDOH, K.; NISHIDA, E. Regulation of MAP kinases by MAP kinase phosphatases. Biochim. Biophys. Acta., v. 1773, p. 1227-1237, 2007. 
KUDAWARA, I.; UEDA, T.; YOSHIKAWA, H.; MIYAMA, T.; YAMAMOTO, T.; NISHIZAWA, Y. In vivo inhibition of tumour growth by dexamethasone in murine osteosarcomas. Eur. J. Cancer, v. 37, p. 1703-1708, 2001.

LAEMMLI, U. K. Cleavage of structural proteins during the assembly of the head of bacteriophage T4. Nature, v. 227, p. 680-685, 1997.

LANGEVELD, C. H.; VAN WASS, M. P.; STOOF, J. C.; SUTANTO, W.; DE KLOET, E. R.; WOLBERS, J. G.; HEIMANS, J. J.. Implication of glucocorticoid receptors in the stimulation of human glioma cell proliferation by dexamethasone. J. Neurosci. Res., v. 31, p. 524-531, 1992.

LASA, M.; ABRAHAM, S. M.; BOUCHERON, C.; SAKLATVALA, J.; CLARK, A. R. Dexamethasone causes sustained expression of mitogen-activated protein kinase (MAPK) phosphatase 1 and phosphatase-mediated inhibition of MAPK p38. Mol. Cell. Biol., v. 22, p. 7802-7811, 2002.

LEE, Y. C.; NIELSEN, J. H. Regulation of beta cell replication. Mol. Cell Endocrinol., v. 297, p. 18-27, 2009.

LEWIS, T. S.; SHAPIRO, P. S.; AHN, N. G. Signal transduction through MAP kinase cascades. Adv. Cancer. Res., v. 74, p. 49-139, 1998.

LINGOHR, M. K.; DICKSON, L. M.; MCCUAIG, J. F.; HUGL, S. R.; TWARDZIK, D. R.; RHODES, C. J. Activation of IRS-2-mediated signal transduction by IGF-1, but not TGFalpha or EGF, augments pancreatic beta-cell proliferation. Diabetes, v. 51, p. 966-976, 2002.

LIU, X.; KIM, C. N.; YANG, J.; JEMMERSON, R.; WANG, X. Induction of apoptotic program in cell-free extracts: requirement for dATP and cytochrome c. Cell, v. 86, p.147-57, 1996.

LIU Y.; PORTA, A.; PENG, X.; GENGARO, K.; CUNNINGHAM, E. B.; LI, H.; DOMINGUES, L. A.; BELLIDO, T.; CHRISTAKOS, S. Prevention of glucocorticoidinduced apoptosis in osteocytes and osteoblasts by calbindin-D28k. J. Bone Miner. Res., v. 19, p. 479-490, 2004.

LONGUET, C.; BROCA, C.; COSTES, S.; HANI, E. H.; BATAILlE, D.; DALle, S. Extracellularly regulated kinases $1 / 2$ (p44/42 mitogen-activated protein kinases) phosphorylate synapsin I and regulate insulin secretion in the MIN6 beta-cell line and islets of Langerhans. Endocrinology., v. 146, p. 643-654, 2005. 
LORTZ, S.; TIEDGE, M.; NACHTWEY, T.; KARLSEN, A. E.; NERUP, J.; LENZEN, S. Protection of insulin-producing RINm5F cells against cytokine-mediated toxicity through overexpression of antioxidant enzymes. Diabetes, v. 49, p. 1123-1130, 2000.

MALONE, M. H.; WANG, Z.; DISTELHORST, C. W. The glucocorticoid-induced gene tdag8 encodes a pro-apoptotic $G$ protein-coupled receptor whose activation promotes glucocorticoid-induced apoptosis. .J Biol. Chem., v. 279, p. 52850-52859, 2004.

MALUMBRES, M.; BARBACID, M. Mammalian cyclin-dependent kinases. Trends Biochem. Sci., v. 30, p. 630-641, 2005.

MARTIN, C. E.; CAKE, M. H.; HARTMANN, P. E.; COOK, I. F. Relationship between fetal corticosteroids, maternal progesterone and parturition in the rat. Acta. Endocrinol., v. 84, p. 167-176, 1977

MARYNISSEN, G.; AERTS, L; VAN ASSCHE, F. A. The endocrine pancreas during pregnancy and lactation in the rat. J. Dev. Physiol., v. 5, p. 373-381, 1983.

MATTERN, J.; BÜCHLER, M. W.; HERR, I. Cell Cycle Arrest by Glucocorticoids May Protect Normal Tissue and Solid Tumors from Cancer Therapy. Cancer Biol. Ther., v. 6, p. 1345-1354, 2007.

MCCLENAGHAN, N. H.; FLATT, P. R. Engineering cultured insulin-secreting pancreatic Bcell lines. J. Mol. Med, v. 77, p. 235-243, 1999.

MILANINI-MONGIAT, J.; POUYSSÉGUR, J.; PAGÈS, G. Identification of two Sp1 phosphorylation sites for p42/p44 mitogen-activated protein kinases: their implication in vascular endothelial growth factor gene transcription. J. Biol. Chem., v. 277, p. 20631-20639, 2002.

MIYAZAKI, J.; ARAKI, K.; YAMATO, E.; IKEGAMI, H.; ASANO, T.; SHIBASAKI, Y.; OKA, Y.; YAMAMURA, K. Establishment of a pancreatic B-cell line that retains glucoseinducible insulin secretion: special reference to expression of glucose transporter isoforms. Endocrinology., v. 127, p. 126-132, 1990.

MORGAN, D. O. Principles of Cdk regulation. Nature, v. 374, p. 131-134, 1995. 
NIELSEN, J. H.; GALSGAARD, E. D.; MOLDRUP, A.; FRIEDRICHSEN, B. N.; BILLESTRUP, N.; HANSEN, J. A.; LEE, Y. C.; CARLSSON, C. Regulation of beta-cell mass by hormones and growth factors. Diabetes, v. 50, p. 25-29, 2001.

NIELSEN, J. H.; SVENSSON, C.; GALSGAARD, E. D.; MØLDRUP, A.; BILLESTRUP, N. Beta cell proliferation and growth factors. J. Mol. Med., v. 77, p. 62-66, 1999.

NURSE, P. Cyclin-dependent kinases and cell cycle control. Chem. BioChem., v. 3, p. 596603, 2002.

OSHIMA, Y.; KURODA, Y.; KUNISHIGE, M.; MATSUMOTO, T.; MITSUI, T. Oxidative stress-associated mitochondrial dysfunction in corticosteroid-treated muscle cells. Muscle Nerve, v. 30, p.49-54, 2004.

PARASKEVAS, S.; AIKIN, R.; MAYSINGER, D.; LAKEY, J. R.; CAVANAGH, T. J.; HERING, B.; WANG, R.; ROSENBERG L. Activation and expression of ERK, JNK, and p38 MAP-kinases in isolated islets of Langerhans: implications for cultured islet survival. FEBS Lett., v.455, p. 203-208, 1999.

PARK, H.; AHN, Y.; PARK, C. K.; CHUNG, H. Y.; PARK, Y. Interleukin-6 protects MIN6 beta cells from cytokine-induced apoptosis. Ann. N. Y. Acad. Sci., v. 1005, p. 242-249, 2003.

PARSONS, J. A.; BRELJE, T. C.; SORENSON, R. L. Adaptation of islets of Langerhans to pregnancy: increased islet cell proliferation and insulin secretion correlates with the onset of placental lactogen secretion. Endocrinology., v. 130, p. 1459-1466, 1992.

PEARSON, G.; ROBINSON, F.; BEERS, G. T.; XU, B. E.; KARANDIKAR, M.; BERMAN, K.; COBB, M. Mitogen-activated protein (MAP) kinase pathways: regulation and physiological functions. Endocr. Rev., v. 22, p. 153-183, 2001.

PETERSEN, H. V.; JENSEN, J. N.; STEIN, R.; SERUP, P. Glucose induced MAPK signalling influences NeuroD1-mediated activation and nuclear localization. FEBS Lett., v. 528, p. 241-245, 2002.

PINES, J. Four-dimensional control of the cell cycle. Nat. Cell. Biol., v. 1, p. 73-79, 1999.

POTOUT, V.; OLSON, L. K.; ROBERTSON, R. P. Insulin-secreting cell lines: classification, characteristics and potential applications. Diabetes Metab., v. 22, p. 7-14, 1996. 
PURTON, P. F.; MONK, J. A.; LIDDICOAT, D. R.; KYPARISSOUDIS, K.; SAKKAL, S.; RICHARDSON, S. J.; GODFREY, D. I.; COLE, T. J. Expression of the glucocorticoid receptor from the $1 \mathrm{~A}$ promoter correlates with $\mathrm{T}$ lymphocyte sensitivity to glucocorticoidinduced cell death. J Immunol., v. 173, p. 3816-3824, 2004.

RANTA, F.; AVRAM, D.; BERCHTOLD, S.; DÜFER, M.; DREWS, G.; LANG, F.; ULLRICH, S. Dexamethasone Induces Cell Death in Insulin-Secreting Cells, an Effect Reversed by Exendin-4. Diabetes, v. 55, p. 1380-1390, 2006.

RIDER, L. G.; HIRASAWA, N.; SANTINI, F.; BEAVEN, M. A. Activation of the mitogenactivated protein kinase cascade is suppressed by low concentrations of dexamethasone in mast cells. J. Immunol., v. 157,p. 2374-2380, 1996.

ROBINSON, M. J.; XU, B. E.; STIPPEC, S.; COBB, M. H. Different domains of the mitogen-activated protein kinases ERK3 and ERK2 direct subcellular localization and upstream specificity in vivo. J. Biol. Chem., v. 277, p. 5094-5100, 2002.

ROSSI, G. .; SHERWIN, R. S.; PENZIAS, A. S.; LAPACZEWSKI, P.; JACOB, R. J.; SHULMAN, G. I.; DIAMOND, M. P. Temporal changes in insulin resistance and secretion in 24-h-fasted conscious pregnant rats. Am. J. Physiol., v. 265, p. 845-851, 1993.

SABBAGH, W. JR.; FLATAUER, L. J.; BARDWELL, A. J.; BARDWELL, L. Specificity of MAP kinase signaling in yeast differentiation involves transient versus sustained MAPK activation. Mol. Cell., v. 8, p. 683-691, 2001.

SAXENA, M.; MUSTELIN, T. Extracellular signals and scores of phosphatases: all roads lead to MAP kinase. Semin. Immunol. v. 12, p. 387-396, 2000.

SUN, H.; CHARLES, C. H.; LAU, L. F. ; TONKS, N. K. MKP-1 (3CH134), an immediate early gene product, is a dual specificity phosphatase that dephosphorylates MAP kinase in vivo. Cell, v. 75, p. 487-493, 1993.

SCAGLIA, L.; CAHILL, C. J.; FINEGOOD, D. T.; BONNER-WEIR, S. Apoptosis participates in the remodeling of the endocrine pancreas in the neonatal rat. Endocrinology., v. 138, p. 1736-1741, 1997.

SCAGLIA, L.; SMITH, F. E.; BONNER-WEIR, S. Apoptosis contributes to the involution of beta cell mass in the post partum rat pancreas. Endocrinology, v. 136, p. 5461-5468, 1995.

SCHONEVELD, O. J.; GAEMERS, I. C.; LAMERS, W. H. Mechanisms of glucocorticoid signalling. Biochim. Biophys. Acta., v.1680, p. 114-128, 2004 
SEARS, R.; NUCKOLLS, F.; HAURA, E.; TAYA, Y.; TAMAI, K.; NEVINS, J. R. Multiple Ras-dependent phosphorylation pathways regulate Myc protein stability. Genes Dev., v.14, p. 2501-2514, 2000.

SENGUPTA, S.; VONESCH, J. L.; WALTZINGER, C.; ZHENG, H. WASYLYK, B. Negative crosstalk between p53 and the glucocorticoid receptor and its role in neuroblastoma cells. EMBO J., v. 19, p. 6051-6064, 2000.

SHAO, J.; QIAO, L.; FRIEDMAN, J. E. Prolactin, progesterone, and dexamethasone coordinately and adversely regulate glucokinase and cAMP/PDE cascades in MIN6 beta-cells. Am. J. Physiol. Endocrinol. Metab., v. 286, p. 304-310, 2004.

SORENSON, R. L.; BRELJE, T. C. Adaptation of islets of Langerhans to pregnancy: betacell growth, enhanced insulin secretion and the role of lactogenic hormones. Horm. Metab. Res., v. 29, p. 301-307, 1997.

TEITELMAN, G.; ALPERT, S.; HANAHAN, D. Proliferation, senescence, and neoplastic progression of beta cells in hyperplasic pancreatic islets. Cell, v. 52, p. 97- 105, 1988.

THEODOSIOU, A.; ASHWORTH, A. MAP kinase phosphatases. Genome Biol., v. 3, 2002.

WRIGHT, K. D.; WRIGHT, A.; DUKE, J. C.; GUSTAFSSON, J. A.: DNA-binding by the glucocorticoid receptor: a structural and functional analysis. J. of Steroid Biochem, Molec. Biol., v. 41, p-249-272, 1992.

WEINHAUS, A. J.; BHAGROO, N. V.; BRELJE, T. C.; SORENSON, R. L. Dexamethasone counteracts the effect of prolactin on islet function: implications for islet regulation in late pregnancy. Endocrinology., v. 141, p. 1384-1393, 2000.

YAMAMOTO, T NISHIGUCHI, M.; INOUE, N.; GOTO, H. G.; KUDAWARA, I.; UEDA, T.; YOSHIKAWA, H.; TANIGAKI, Y.; NISHIZAWA, Y. Inhibition of murine osteosarcoma cell proliferation by glucocorticoid. Anticancer Res., v. 22, p. 4151-4156, 2002.

YOON, S.; SEGER, R. The extracellular signal-regulated kinase: multiple substrates regulate diverse cellular functions. Growth Factors., v. 24, p. 21-44, 2006.

ZIBERA, C.; GIBELLI, N.; BUTTI, G.; PEDRAZZOLI, P.; CARBONE, M.; MAGRASSI, L. ROBUSTELLI DELLA CUNA, G. Proliferative effect of dexamethasone on a human 
glioblastoma cell line (HU 197) is mediated by glucocorticoid receptors. Anticancer Res., v. 12, p.1571-1574, 1992. 